\title{
Students' multimodal knowledge practices in a makerspace learning environment
}

\author{
Anu Kajamaa ${ }^{1}$ (D) Kristiina Kumpulainen $^{1}$ (D) \\ Received: 24 April 2020 / Accepted: 26 November 2020/Published online: 2 January 2021 \\ (C) The Author(s) 2021
}

\begin{abstract}
In this study, we aim to widen the understanding of how students' collaborative knowledge practices are mediated multimodally in a school's makerspace learning environment. Taking a sociocultural stance, we analyzed students' knowledge practices while carrying out STEAM learning challenges in small groups in the FUSE Studio, an elementary school's makerspace. Our findings show how discourse, digital and other "hands on" materials, embodied actions, such as gestures and postures, and the physical space with its arrangements mediated the students' knowledge practices. Our analysis of these mediational means led us to identifying four types of multimodal knowledge practice, namely orienting, interpreting, concretizing, and expanding knowledge, which guided and facilitated the students' creation of shared epistemic objects, artifacts, and their collective learning. However, due to the multimodal nature of knowledge practices, carrying out learning challenges in a makerspace can be challenging for students. To enhance the educational potential of makerspaces in supporting students' knowledge creation and learning, further attention needs to be directed to the development of new pedagogical solutions, to better facilitate multimodal knowledge practices and their collective management.
\end{abstract}

Keywords Knowledge practices $\cdot$ Mediation $\cdot$ Multimodal $\cdot$ Makerspace $\cdot$ Learning environment

Introduction Makerspaces have aroused recent interest as they serve as novel forms of technology- and materially rich learning environments (Honey and Kanter 2013; Halverson and Sheridan 2014; Kafai et al. 2014, Kumpulainen et al. 2020; Marsh et al. 2017; Peppler et al. 2016). They account for interest-driven engagement in creative activities with a range of digital and hands-on tools and artifacts (Kumpulainen and Kajamaa 2020; Mehto et al. 2020; Riikonen et al. 2020). For many, these spaces constitute ways of reaching educationallyprogressive goals that are not easily realized in more traditional educational practices, such as

Anu Kajamaa

anu.kajamaa@helsinki.fi

1 Faculty of Educational Sciences, University of Helsinki, Helsinki, Finland 
valuing students' problem-finding, inventive seeking of solutions and peer assessment (Blikstein 2013; Halverson and Sheridan 2014; Schrock 2014; Smith and Smith 2016). It has been suggested that makerspaces offer a powerful context to foster students' science, technology, engineering, art and mathematics (STEAM) learning. Furthermore, makerspaces are regarded as accommodating a diversity of interests and levels of engagement (Johnson and Halverson 2015), enhancing students' twenty-first century skills, such as collaboration and digital literacy skills, crucial for working and functioning in contemporary society (Bevan et al. 2016; Peppler et al. 2016). It has also been reported that technology-rich makerspaces enhance students' digital competencies, providing them with ample opportunities to engage in social practices that entail making and creating artifacts and texts through generative use of various materials and technologies (Marsh 2020).

However, previous studies on technology- and materially-rich learning environments have also illuminated how the introduction of digital resources and multiple tools can create tensions when the students' personal interests and the instructions given by the teacher do not match, thus complicating teacher-student interaction (Greiffenhagen 2012; Kajamaa et al. 2020; Rasmussen and Damşa 2017; Strømme and Furberg 2015). In makerspaces this is especially the case, as the design tasks and projects are usually complex and built by heterogeneous learner groups (i.e., students with different knowledge resources), tools, artifacts and practices, and involve a nonlinear organization of collaboration and knowledge-creation processes (Riikonen et al. 2020; Stahl and Hakkarainen 2020), posing challenges for students and their teachers. Moreover, maker-centered learning is challenging for researchers to investigate as design and making activities typically take place "around" rather than "through" CSCL technologies (Stahl and Hakkarainen 2020). Adding to the complexity, the technologicallyand materially-mediated creative processes often involve surprises and dynamic interactions that are difficult regulate, predict and script (Sawyer 2012; Yeh et al. 2012). The level of students' collaborative engagement also varies in makerspaces, some students taking more responsibility than the others over the making processes, such as coordination of joint work, seeking out resources, and offering guidance and support to others (Leskinen et al. 2020). Furthermore, the heterogeneity of learners and the multiple social, discursive and material means involved (Mehto et al. 2020; Riikonen et al. 2020) point to "the complex texture of knowledge as practiced" (Knorr-Cetina 1999, p. 2) in educational makerspace contexts.

Recently, calls have been made for CSCL processes to be investigated at the level of practices (Stahl and Hakkarainen 2020) and for developing ways of supporting students' knowledge practices (Damşa and Muukkonen 2020). In this study, our aim is to widen the understanding of how students' collaborative knowledge practices are mediated multimodally in a school's technology- and materially rich makerspace environment. To widen the educational potential of makerspaces, and to support students' knowledge creation and learning in these, further research attention needs to be paid to the reciprocal interaction between knowledge creation and students' collaborative practices. Moreover, further research needs to be directed towards the processes of collective knowledge creation, which takes place through interactive practices. Such open-ended and dynamic epistemic practices through which people jointly create and develop knowledge (KnorrCetina 2001), in other words, knowledge practices, can channel students' intellectual efforts, further inquiries, and collective learning processes (Hakkarainen 2009; Hakkarainen et al. 2004; Stahl and Hakkarainen 2020; Zhang et al. 2018), thus forming an important area of further research in technology- and materially-rich learning environments. With this research interest in mind, we investigate students' multimodal 
knowledge practices within a school-based makerspace, and ask the following research questions:

How do different types of talk contribute to students' interaction and creation of knowledge when carrying out STEAM learning challenges in a makerspace?

How do language and other mediational means mediate students' knowledge practices in a makerspace?

Which multimodal knowledge practices can be identified and how are they collaboratively enacted by the students in their design and making processes?

Our empirical study was undertaken in a makerspace called the FUSE Studio within a public comprehensive school in Finland, which had undergone a curriculum reform from 2016 onwards. The new national core curriculum has a strong emphasis on students' interest-driven learning and student engagement, with a special focus on the development of the students' digital and learning-to-learn skills. Traditionally, in all Finnish schools, design and creation of artifacts have already been included in craft education for a century, which is an obligatory school subject, now enriched with digital fabrication technologies. The FUSE Studio makerspace was built within the school and introduced as one of the school's elective courses in 2016, providing pre-defined STEAM learning challenges and tools for students participating in scientific, engineering and design practices, and creative ways of working with knowledge. It can thus be viewed as a potential tool for the teachers to integrate the next generation standards for science education (National Academy of Sciences 2012). As a course included in the local curriculum, it can also be regarded as a long-term project and an effort aimed at creating educational change within the school. The FUSE Studio concept was originally created at Northwestern University in the US (see: www.fusestudio.net) and in addition to this school, it is currently being adopted also in five other schools in Finland as part of a curriculum reform effort.

The core idea of the FUSE Studio is that, with the help of digital and non-digital tools, it can promote students' STEAM learning and to cultivate STEAM ideas and practices among those who are not already familiar with them, and by so doing broadening access to participation in STEAM learning (Stevens et al. 2016; Stevens and Jona 2017). Even though the 30 different STEAM challenges are provided to the students in this context, they are still "open ended", allowing for diverse solution paths, creativity and innovation. In other words, the students have a substantial say in how they engage in the design and making activities and with whom. In the school in focus in this investigation, students are able to use the school's computer lab, one regular classroom and the corridor, for carrying out the challenges, such as to build a dream home with 3D modelling software or to make windmills, solar-powered cars, laser mazes, or roller coasters. This type of maker work requires continuous sketching and prototyping from the students. From the teachers' perspective, FUSE offers the opportunity for low threshold activity in terms of providing a natural context for peer tutoring and not requiring advanced digital competence from the teachers themselves.

Within this sociocultural context, we view knowledge and human activity as cultural and deeply contextual and oriented by historically specific social organization, in our case, the school where the FUSE Studio makerspace is located. We locate language and tool-mediated social interactions at the center of the analysis of knowledge creation and human learning (Vygotsky 1978; Säljö 1999; Ludvigsen et al. 2011). Further, we consider talk to be a pivotal mediator in student participation within peer interaction and collaborative processes, and in their learning (e.g. Rowell 2002; Mercer et al. 2019; Mercer 2005). Together with language, tools and artifacts are at the center of our research attention, aiding the externalization of the 
participants' internal mental work (Vygotsky 1978). The externalization is pivotal because it enables the ideas and tools to be appropriated by others, enhancing their further use and refinement, as well as collaborative learning (Baker et al. 1999). Further, we view social action and tools (both conceptual and tangible) as intertwined resources (see also Ingold 2010; Mäkitalo 2011) that will make possible particular kinds of actions that come into being via social, embodied actions in a certain cultural setting (Goodwin 2003).

From a sociocultural view, we perceive knowledge practices as a collective phenomenon emerging from interaction and joint learning efforts, not the independent actions carried out by individual participants. We thus define students' knowledge creation as a social practice (Knorr-Cetina 2001), with knowledge practices guiding the students' learning and shared practical understanding of their learning activity (Hakkarainen et al. 2004, Hakkarainen 2009; Seitamaa-Hakkarainen et al. 2010). By social practices we refer to the recurring patterns of activities, which are embodied and mediated by language and tools, artifacts that are grounded in epistemic objects and artifacts, and shared by the participants of a certain community (Schatzki 1996; Schatzki 2001; Schmidt and Volbers 2011; Miettinen 2006). Moreover, we view the processes of collective knowledge creation taking place through interactive practices that contribute to ideas and learning being materialized into shared epistemic (i.e., knowledge) objects and artifacts (Riikonen et al. 2020; Mehto et al. 2020; Paavola et al. 2011).

On this basis, we carried out sociocultural discourse analysis (Mercer et al. 1999; Mercer 2005, also Mercer 2019) complemented with a multimodal interaction analysis (Goodwin 2003; Kress 2010; Streeck et al. 2011; Taylor 2014), focused on digital and hands on materials, embodied actions and spatial arrangements, to analyze students' interaction, socio-material mediation and collaborative knowledge practices when carrying out the FUSE learning challenges. As our original contribution, this led us to identify four, intertwined knowledge practices; namely, orienting to, interpreting, concretizing, and expanding knowledge. These practices guided and facilitated the students' creation of shared epistemic objects, artifacts, and their collective learning in the FUSE Studio makerspace.

\section{Students' knowledge creation in technology- and materially rich learning environments}

Knowledge creation has been a central theme among scholars interested in students' learning (see e.g., Bereiter and Scardamalia 2014; Brown and Duguid 2017; Kump et al. 2013; Mercer 2005; Mercer et al. 2019; Cress and Kimmerle 2008; Scardamalia 2002). During the knowledge creation process, the students share their different ideas, engage in individual and collective interpretation and meaning-making processes, and thus influence the thinking and the productive activities of one another (Arvaja et al. 2007). This process may also involve collaborative practices of problem definition and problem solving (Hennessy and Murphy 1999), and exploration of new knowledge, ideally leading the actors to transcend the boundaries between old and new knowledge. When students are viewed as active creators of knowledge, taking collective responsibility over their learning (Scardamalia and Bereiter 2014; Scardamalia 2002; Zhang et al. 2009), technology-rich learning environments are able to provide opportunities for the emergence of their epistemic agency, in other words, the ways the students engage in improving their ideas collectively (Scardamalia 2002; Scardamalia et al. 2012; Damşa et al. 2010). 
As shown by previous classroom-based studies, the production of new knowledge and advancement of individual knowledge usually requires interaction and collective effort during collaborative tasks (Damșa et al. 2010; Fernández et al. 2009; Ludvigsen et al. 2016; Mercer 1994; Wegerif 1996). Language functions as a particularly important medium for collaborative knowledge creation and for developing the students' thinking, ideas and learning (Mercer 2005; Mercer and Littleton 2007). Language is an important mediational means for the students' dialogue, which may also be referred to as "productive discourse engagement" (Scardamalia 2002), and for their successful collaborative creation of new knowledge (e.g., Bereiter and Scardamalia 2014; Cress and Kimmerle 2008). Further, the social experience of language use significantly shapes individual cognition, the dialogic interaction raising students' awareness of their collaborative talk (Mercer et al. 1999; Wertsch 1991). Moreover, "in dialogues, the students gain the psychological benefit of the historical and contemporary experience of their culture" (Mercer et al. 1999, 96). In sum, the student's adoption of a "social mode of thinking" (Mercer 1995) and their induction into ways of using language for seeking, sharing and constructing knowledge is crucial for their collaborative work and learning (Mercer 1995, 1996; Rojas-Drummond et al. 1998; Mercer et al. 1999).

During collaborative learning, students work together on a common problem and their interaction enhances knowledge sharing, joint knowledge creation and the development of shared understanding (Hmelo-Silver 2003). However, the interacting students possess different knowledge, with some being less and some being more knowledgeable than others (e.g. Brown and Campione 1996), which creates challenges and tensions in collective knowledge creation (Ludvigsen 2012). For instance, it can be challenging for the students to reflect on their knowledge and to explain it (Mercer 2008), to ask each other questions, and to explain and to clarify their own ideas and opinions, and to elaborate the reasoning behind these (Kollar et al. 2006; Martin and Hand 2009), or to take alternative views into consideration (Sampson et al. 2011). Therefore, much basic knowledge is often left implicit, creating misunderstandings in classrooms and in other settings (Mercer 2008).

Learning arrangements with technological infrastructures have been introduced to provide better opportunities for student interaction, collaboration, knowledge creation and conceptual advancement (Scardamalia and Bereiter 1994), allowing the students to improve ideas collaboratively (Scardamalia 2002; Scardamalia et al. 2012; Damşa et al. 2010). Such environments can also entail the transformation of the spatial and temporal relations of student learning and pedagogical activities, for instance by breaking traditional spatial and temporal boundaries of learning, making remote information sources accessible and collaborative learning location-free (Ritella and Hakkarainen 2012; Suthers 2006).

By emphasizing students' own choice and interest and connecting the educational learning activities to their everyday lives and communities outside the school, technology- and materially-rich learning environments can also create local or online "hybrid spaces" for teaching and learning in which the formal and everyday creatively intersect (see Gutiérrez et al. 1999; Ludvigsen 2012; Kajamaa et al. 2018). The novel technological infrastructures and learning arrangements also allow students to relate to materiality and to transform it in new ways, as the students are typically invited to act creatively to modify and develop material objects as part of the learning process (Kumpulainen et al. 2019a, b). The different knowledge resources available can accumulate collective knowledge and experience, thus having an instrumental value (Miettinen and Paavola 2016) for the students' learning (see also Engeström 2007). 
In the context of schools, to enhance computer supported learning, increasing research attention has been paid to reciprocal interaction between students' knowledge creation and practice, introducing the notion of knowledge practices, useful in taking us beyond researching and analyzing "mere" knowledge and "mere" practice. By definition, knowledge practices (i.e., epistemic practices) can refer to discursive practices in relation to knowledge (Sandoval and Reiser 2004). Knowledge-creation learning can be understood "to be dependent on materially embodied practices rather than mere conceptual experiences" (Hakkarainen 2009, p. 224). It can include the utilization and creation of a variety of digital and non-digital tools and artifacts, with language mediating the students' activity (Kumpulainen and Kajamaa 2020; Kumpulainen et al. 2019; Mehto et al. 2020; Riikonen et al. 2020), and channeling the participants' collective learning processes (Hakkarainen 2009; Hakkarainen et al. 2004; Stahl and Hakkarainen 2020). In materially-rich makerspaces, solving and managing the complex knowledge problems can involve all of the students' senses, such as looking, touching, feeling and listening (Koskinen et al. 2015), contributing to the creation and usage of different types of epistemic (i.e., knowledge) objects and artifacts. Furthermore, when working interactively with learning challenges and materials, students utilize tools for making their tacit knowledge explicit (Illum and Johansson 2012), adding to their accumulated cultural knowledge (Koskinen et al. 2015). In these contexts, the materialization of the knowledge objects is critically dependent on embodied practices connected to making (Kangas et al. 2013; Blikstein 2013; Kafai et al. 2014). The objects are usually negotiated and defined by the students and left more open-ended than traditional 'objects' (Hakkarainen 2009).

Furthermore, along with language and materiality, embodied resources are pivotal for grasping the unfolding of working processes, and in advancing the creative process (Härkki et al. 2017) in makerspaces. Also, the available structures, resources and arrangements of the context are important for enhancing student engagement (Kangas et al. 2013; Kumpulainen et al. 2018), which can be seen as a means of supporting students' transformative agency, in other words, transformation and reframing of the collective activity resulting from their learning via creative utilization of various resources available in the makerspace (Kajamaa and Kumpulainen 2019). In this study, we analyzed how students' collaborative knowledge practices are mediated multimodally in a FUSE Studio makerspace environment in which they carry out STEAM learning challenges.

\section{Empirical study}

\section{Research setting}

The context of this study is a public comprehensive school with 535 students and 28 teachers at the primary level. The school strives for student-centeredness and stresses design and digital learning, which aims to enhance students' creative problem-solving skills across the curriculum. In 2016, as a response to the new national core curriculum requirements, the school introduced the FUSE Studio as one of its elective courses.

The FUSE Studio was situated in the school's computer lab, with a neighboring classroom space and the nearby corridor for the students to use as needed. There were 22 desktop computers and separate laptops available for the students, and a rich variety of hands-on materials. While taking part in the FUSE Studio session, the students are able access the learning challenges and their associated instructions through a website (www.fusestudio.net). 
The instructions provided by the FUSE Studio program offer students "a stimulus" for their maker work, and a vision or image of the object, which will then, via the process of design and development, transform as well as materialize into a shared epistemic object or (tangible) artifact. Through this process, it is our view that the notion of "epistemic" refers not only to knowledge, but also to material artifacts and the ideas out of which they are constructed. Fig. 1 shows the students' view of the digital FUSE Studio environment on which the students find trailer videos of each challenge and choose the challenge most appealing to them.

More specifically, the FUSE Studio consists of a computer program and hands-on material packages including 30 (pre-given) activities, called challenges, from which the students are free to select the challenge most appealing to them, with whom to pursue it (or alone), and when to move on, progressing at their own pace. The technological and pedagogical infrastructure of the FUSE Studio consists of digital tools (computers, 3D printers) and other materials (e.g., foam rubber, a marble, tape and scissors). The learning challenges students engage in range from designing jewelry to building a dream home with 3D modelling software, to making windmills, solar-powered cars, laser mazes, and roller coasters. Some of the challenges are fully digital and in others, students use physical materials that are provided to them in separate kits. The design challenges level up in difficulty following the basic logic of video game design principles (see e.g., Holbert and Wilensky 2014). During the FUSE

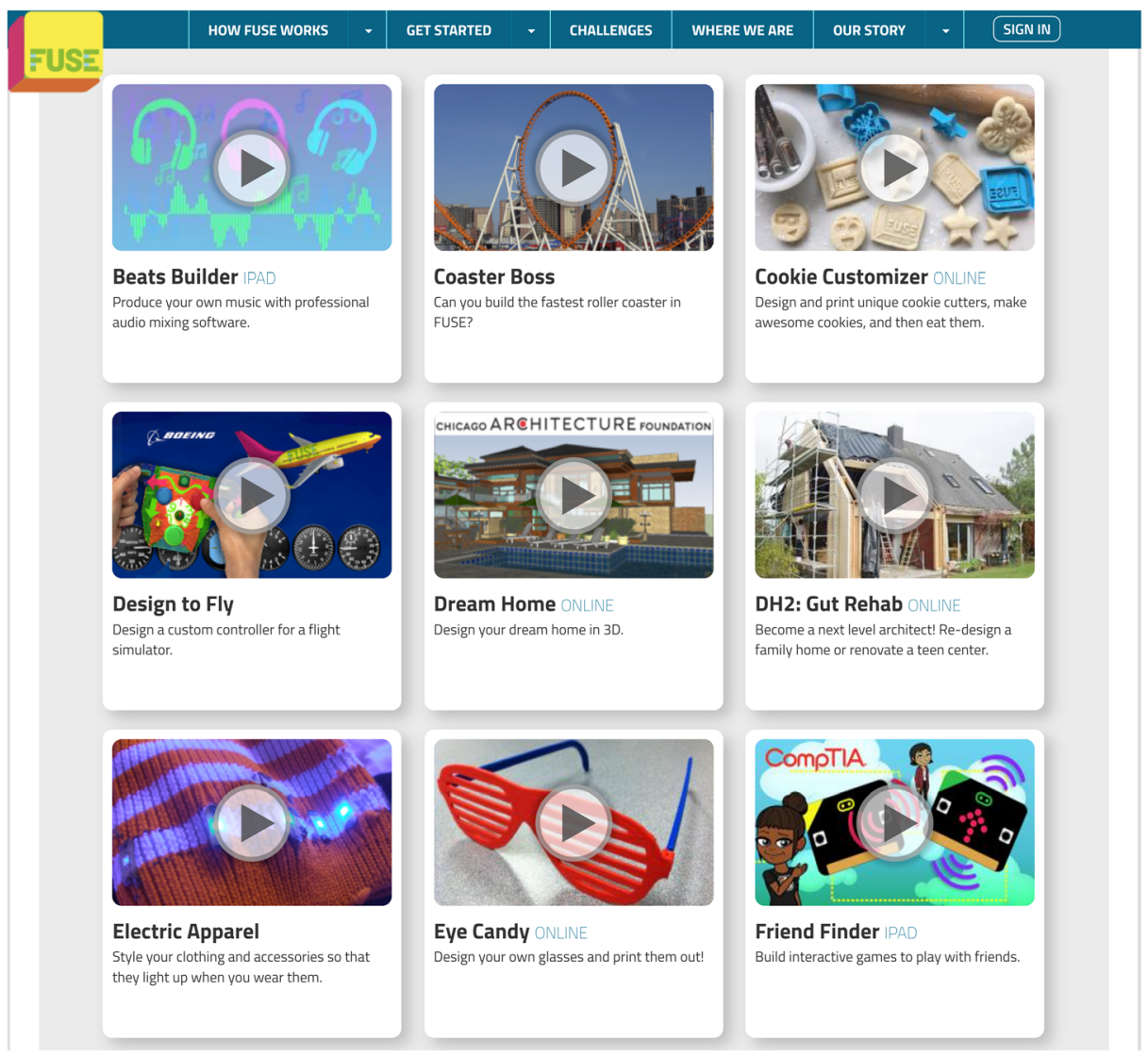

Fig. 1 "My Challenges" student interface 
studio sessions, the teacher(s) make rounds throughout the makerspace to follow how the students' work progresses (Greiffenhagen 2012; Koskinen et al. 2015). The students can also call upon teachers and their peers (in other groups) when needed. The assessment of a student's participation and learning does not include grading, but is carried out by using photos, video or other digital artifacts and the student's own documentation (Stevens and Jona 2017). Failures are viewed as just another try, and as significant experiences during the processes of making (Hilppö and Stevens 2020).

\section{Data collection}

The video recordings were collected intermittently during one academic year of participation within the makerspace. We collected data three times a week from August to December 2016. The data comprised $111 \mathrm{~h}$ of transcribed video recordings, and our field notes about groups of students $(N=$ 94, age 9-12 years) and their facilitator-teachers $(N=7)$ in the FUSE Studio. The students' guardians were informed about the research and its data collection methods and were asked to give their written consent for their children's participation. Participation in the research was voluntary and could be ended at any time. The research respects the teachers' and children's anonymity and privacy, and all names mentioned in the research are pseudonyms. The data were taken from three groups of students who had chosen the FUSE Studio as an elective course for the 2016-2017 academic year. In particular, Group 1 consisted of 32 4th graders ( 22 boys and 10 girls), Group 2 of 30 5th graders (19 boys and 11 girls), and Group 3 of 32 6th graders (19 boys and 13 girls). Each group had one 60-min FUSE session per week. Each group had two appointed teachers to support student work in the FUSE Studio.

In the FUSE Studio, we used four video cameras to capture the moment-by-moment activities of the students and teachers. Usually, two of the cameras followed the teachers and two were set to record selected students' work. The main principle that guided the decisions regarding the focus of the cameras for each session was the need to form a comprehensive picture of the nature of interaction and activities. On each of the videos, we had one camera that was set to film the group. The angle was adjusted according to the students' movement in the space. The computer screens and other "hands-on" materials were captured as parts of the students' interaction as visible within the scene. We did not specifically zoom in for close-up shots of the computer screens. The following photographs (captured from the videos) providing an example of our videoing of a group working in the computer lab area of the FUSE Studio.

For this study, we selected $350 \mathrm{~min}$ of the transcribed video data focusing on two groups working together on several FUSE challenges. One group was a group of four boys pseudonymized as Leo, Alex, John and Mark (photos of their work are shown in the findings section). The other was a group of four girls pseudonymized as Nellie, Emmi, Sara and Nora (photos of their work are shown in Fig. 2 above). The total duration of the data from the girls' group was $185 \mathrm{~min}$, and from the boys, $165 \mathrm{~min}$ (350 $\mathrm{min}$ in total). Each group was supported by two to four teachers and teaching assistants. We selected these two groups as we wanted to follow those students who had previously worked as a group in the FUSE studio with a broad range of STEAM learning challenges, and who used various spaces and materials within the FUSE Studio makerspace (i.e., the computer lab, the neighboring classroom space, and the corridor). It was also a goal to include a group of girls and a group of boys. The two groups worked on STEAM challenges in which they needed to collaborate to design a shared epistemic object and also construct a (tangible) material artifact, to which the created ideas materialize. Further, one of our selection criteria for these two groups was that these student groups worked purposefully and completed the FUSE challenges during a single session. 

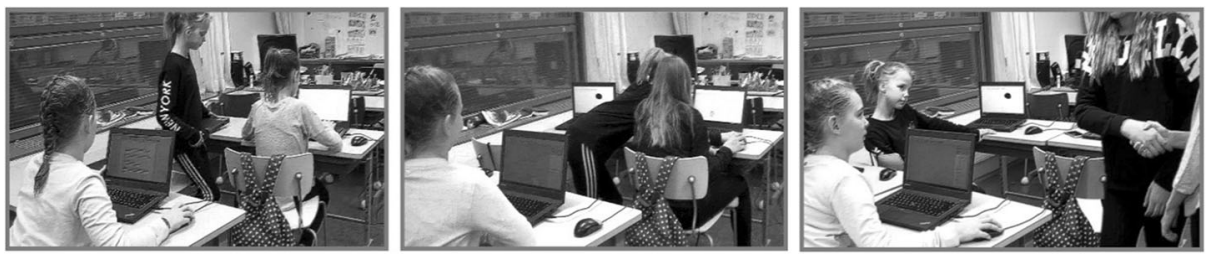

Fig. 2 Here we display photos of Nellie, Emmi, Sara and Nora illustrating the orientation of the camera within the makerspace

This was not always the case in other groups, as students often continued with the same challenge in subsequent session(s). Due to space limitations, and the detailed nature of the analysis, we present only selected parts of the examples, often focusing only on two students in the group.

One advantage from an analytic perspective in selecting these two groups in particular is that while the group work practices we observed in these groups appeared similar to the work in other groups, these students worked in the same groups over many session and multiple design challenges. The other students changed the composition of their groups more often than these two groups. All students participating in our study had taken part in craft education classes (included as part of the national core curriculum) as part of their schoolwork, hence working on design tasks in the FUSE studio cannot be regarded as a totally novel activity to the students. Further, we analyzed these particular examples with reference to the information from the whole corpus of our video data (all $111 \mathrm{~h}$ ). For the analyses of the other four teams, the interested reader may refer to separate articles (Kumpulainen et al. 2020; Leskinen et al. 2020). We acknowledge that if the groups had just started to work in FUSE studies, the results of analyses might have looked different.

\section{Data analysis}

We first approached the data more holistically and then focused on selected events in greater depth as explained below (Derry et al. 2010). First, we uploaded the $111 \mathrm{~h}$ of videotaped and transcribed FUSE sessions into the Atlas.ti analysis software, to view and to read as a whole, to identify student groups in which the students stayed over several FUSE Studio sessions and who worked on those design challenges that involved active and sustained use of digital technologies in the FUSE Studio makerspace. Based on consensus (via researcher negotiations), this resulted in selecting $350 \mathrm{~min}$ of video data of two student groups working with three different STEAM learning challenges in different spaces, for presentation in this study. Our in-depth analysis then included the following three sequential phases.

To respond to our first research question on how different types of talk contribute to students' interaction and creation of knowledge, we analyzed the $350 \mathrm{~min}$ of video-data to find out how language contributed to students' interaction and joint creation of knowledge when carrying out the STEAM learning challenges. This first phase of the analysis was abductive, involving repeated iterations between theory and the data (Van Maanen et al. 2007). We coded the videos by applying sociocultural discourse analysis, providing us with the typology for the analysis of three "archetypical forms" of students' talk; Cumulative, Disputational and Exploratory (see Mercer et al. 1999; Mercer 2005, also Mercer 2019). We coded speaking turns during the students' interaction in which they constructed common knowledge via accumulation, repetition, conformation and elaboration of statements and suggestions, in other words cumulative talk. We searched for short utterances and instances of assertion and counter- 
assertion, and in which the student's competed with each other, ignored the other, challenged or criticized the other, namely disputational talk. We also coded speaking turns in which the students actively contested each other, critically but constructively in their engagement with each other's opinions, statements and suggestions, made joint decisions and their reasoning and knowledge was made publicly accountable, in other words exploratory talk.

To respond to our second research question on how language and other mediational means serve to mediate students' knowledge practices, we viewed the videoed data again and carried out a multimodal interaction analysis (Goodwin 2003; Kress 2010; Streeck et al. 2011; Taylor 2014) across the $350 \mathrm{~min}$ of data. This second phase included our identification of the material, embodied, and spatial resources involved in the students' interaction during their maker activities. More specifically, we analyzed the students' knowledge creation as embodied and materially and spatially mediated, and as evolving through and within the students' interaction. We coded parts of the data in which these resources mediated the students' joint attention, in other words, their capacity to coordinate actions and attention with others on an object (see Tomasello 2000). We coded the topics, concepts and notions mentioned by the students while making inquiries and solving problems, allowing us to identify the emergence of joint attention and the core epistemic (knowledge) objects during their maker work. We also coded parts of the interaction in which (tangible) epistemic material artifacts were discussed, created, appropriated (also Baker et al. 1999) and used, paying special attention to the students' use of the physical space and its arrangements. We also coded verbal and non-verbal embodied actions and signals, such as postures, gestures, gazes and physical movement (such as moving closer and withdrawing from the interaction) (see Mondada 2018), related to the creation and use of epistemic objects and artifacts, and mediating their handling. We also engaged in relating our analysis to the existing literature on the role of socio-material mediation (Vygotsky 1986; Säljö 1999; Ludvigsen et al. 2011) and embodiment (Härkki et al. 2017) in students' collective activity. Note that any one instance of multimodal interaction could be coded with more than one code.

As our third analytical phase, in response to our third research question on the identification of multimodal knowledge practices and their collaborative enactment by the students, we re-viewed the parts of the video data that we had coded in the discursive and multimodal interaction analysis, to analyze the data further, to identify the students' multimodal knowledge practices guiding and facilitating their learning during the design and making activities. In the videos, we focused our attention on depicting the student groups' recurring patterns of activities mediated by types of talk and other mediational means, such as the embodied actions used as a complementary channel to express and demonstrate ideas to others (Taylor 2014), we had identified in our two earlier analytical phases. In this phase, our analytical interest was in exploring how the knowledge practices, involving epistemic (knowledge) objects and their materialization to (tangible) artifacts are enacted and became shared by the students and their peers in guiding and facilitating the students' joint attention, knowledge creation and learning in the FUSE Studio makerspace. In this, we related our data-driven analysis to the existing literature on joint attention (see Tomasello 2000), knowledge practices (Hakkarainen et al. 2004; Hakkarainen 2009; Seitamaa-Hakkarainen et al. 2010; KnorrCetina 2001), and to the instructions for carrying out the STEAM learning challenges, provided by the FUSE Studio program in the website (www.fusestudio.net). This led us to identifying four, intertwined knowledge practices namely orienting to, interpreting, concretizing, and expanding knowledge which we viewed as constitutive of the students' activity in the FUSE Studio.

To ensure inter-coder reliability, the primary coder first analyzed videos using the Atlas.ti software, applying our emergent analysis framework. To establish the reliability of the analysis, the second coder scored a representative sample of the data by applying the same 
analysis framework. We discussed any disagreements in coding (e.g. some of the coding rules were further clarified) until there was agreement.

\section{Findings: Students' multimodal knowledge practices in the FUSE studio}

Here we discuss our findings in relation to the interactional situations that characterized the students' collaborative knowledge practices in our video data. The four, intertwined, multimodal knowledge practices that we identified, namely orienting to, interpreting, concretizing and expanding knowledge, are first defined. Thereafter, we will present three episodes, each including the four multimodal knowledge practices via discursive, material, embodied and spatial dimensions of analysis.

(1) Orienting to knowledge emerged in our data through discourse and embodied actions when the student groups began their design and making processes. The students prepared themselves to conduct a STEAM learning challenge by first selecting who to work with, and as a group positioned themselves (by bodily acts, such as taking an independent or collaborative stance) in the physical space of the FUSE Studio and its organization, such as the furniture and the computers. By utilizing the "My Challenges" interface in the FUSE Studio program (see Fig. 1), they then decided which STEAM learning challenge they were interested in working with, and began to familiarize themselves with its instructions, presented on the FUSE website. As an indication of their interest, the students usually expressed their intention (verbally or through gesture) to pursue a certain challenge. In this, talk, embodied actions, and material and spatial mediators mediated and coordinated the students' joint attention and engagement. The ways in which the student groups used language mediated the nature of their engagement and the atmosphere of their social interactions. Their process of orienting to knowledge typically involved cumulative talk, in other words, the students' construction of common knowledge via confirmation and repetition of the instructions in the computer program. It also included the students (verbal and embodied) selection and appropriation of the materials and spaces, such as by selecting the space for their work on the challenge. In some cases, we were also able to witness disputational talk, such as assertion and counter-assertion, competing, or at times even ignoring each other.

(2) Interpreting knowledge refers to the students verbally reflecting on the given instructions and ideating further about how to proceed with the challenge and in their problem solving. Moreover, the interpretation efforts between the students was evidence of their attempts to achieve a shared understanding. The interpretation involved the students' construction of common knowledge via cumulative talk. They began offering information to each other by sharing and exchanging their existing knowledge and experiences in relation to the various materials, tools and the problem at hand. This also included preliminary visioning, planning and ideating the next steps of the design and making process. This included the students' usage of the computer program for designing epistemic objects and artifacts, and their search and familiarization of themselves with other materials, such as foam rubber, a marble, tape, scissors, and 3D printers. It also included disputational talk. For instance, the students questioned and reframed the given circumstances in terms of deciding not to follow the instructions of the FUSE Studio. It also included the students (verbal and embodied) judging of the existing arrangements, materials and spaces, such as moving to work in the corridor. They also carried out re-positioning (by bodily acts) themselves and the materials within the makerspace when something was not functioning in an orderly fashion, to better coordinate their collaborative work. 
(3) Concretizing knowledge involved students' externalizing of their knowledge creation process into different knowledge (i.e. epistemic) objects and material / tangible artifacts. The students made creative acts of explaining and working with the available conceptual, material and spatial resources and made initiatives and plans to use the existing objects and artifacts, and to create new ones. The students viewed and engaged in the actions by exploring ways of working, demonstrating, seeking help, coordinating and moving back and forth in their making process (by verbal and embodied actions), to solve the problems involved in the learning challenge. In their joint search for solutions, they usually negotiated, adjusted, agreed and further elaborated their ideas. Also, when concretizing their visions, ideas and plans into epistemic objects and material artifacts, the student talk often exemplified disputational talk, as the students disagreed and contested one another. They also exemplified exploratory talk, when they actively contested each other, constructively engaged with each other's opinions, statements and suggestions, and made joint decisions. The decision making often also involved acts of disregarding many of the proposed, optional ways to proceed with the challenge, and collective appropriation of certain suggestions, leading to collaborative distillation (i.e. a participant first shifts away from what he believes to be unsuitable and then the other follows) of the solutions and the concretizing of the knowledge into shared (epistemic, digital) objects and (tangible) artifacts meaningful to the participating students.

(4) Expanding knowledge related to situations in which the students critically but constructively engaged in further planning, coordinating and carrying out the learning challenge. This took place when they encountered difficulties in the design and making process, disagreed, or were not satisfied with the process, after which they had to expansively either reject, modify or entirely revise their epistemic object in making, often exemplifying disputational talk. Further, their knowledge was made publicly accountable through discourse and can be defined as joint reasoning, featuring exploratory talk. They then often changed their original plan, the direction of their making, redefined the usage of certain tools, iterated, further demonstrated (by embodied actions) and repeated parts of the process. The goal of this process was to solve the problem, and to create a more satisfying shared epistemic object or artifact. They also assessed their design and making processes and expressed a collective will to ignore, alter or expand the pre-given instructions. This appeared to result in the emergence of the students' expanded understanding of the situation and the process as a whole, as well as expansion of the specific knowledge object or artifact in progress, to improve its functionality and meaningfulness as a co-created outcome of the activity.

\section{Episode 1: Proceeding with the challenge in the corridor to create a security system}

In this episode, it is possible to see how discourse, digital and other "hands on" materials, embodied actions, such as gestures and postures, and the physical space with its arrangements mediated the students' collaborative knowledge practices (i.e. orienting to, interpreting, concretizing and expanding knowledge). In this episode, the boys used the FUSE Studio materials and spaces in creative ways and relocated their maker work from the computer lab to the nearby corridor. The learning challenge was new to the boys in the group and they shifted from first relying on the pre-given instructions to actively ideating and exploring alternative paths for proceeding with the complex challenge. In many parts of the episode, we were able to witness the dominance of non-verbal (embodied) actions, and material and spatial mediation, 
mediating joint attention, coordination and knowledge creation. The students often engaged with each other's ideas critically, but mainly constructively, and took alternative and expansive directions to proceed with the challenge. Despite their dispute and fact that multiple times, their attention was drawn away from the challenge by their peers, they finally successfully completed their Laser Defender.

The four boys, (pseudonymized as) Leo, Alex, John and Mark, began orienting to the challenge by deciding to work as a group, and by positioning themselves by sitting down in pairs on the desks in the computer lab. They then choose to work on the "Laser Defender" learning challenge, in which the students create a laser beam security system to protect a valuable "treasure" and challenge their friends to break in. (For more information, see: www. fusestudio.net/challenges). The Laser Defender challenge was new to all four boys, making it impossible to exchange any prior knowledge and experiences in relation to it. When sitting in two separate rows in the computer lab, they decide to continue with the challenge in pairs, to create their own security systems, to which the other pair could then try to break in.

At the beginning of the making, Leo is sitting by his computer, trying to open the "My Challenges" interface to get access to the instructions for the challenge from his computer screen. Alex is quietly standing behind him, positioned by the toolbox, handling and selecting some of the tools as needed, and orienting to the challenge. John comes to stand by him and states that he had already started the challenge with Mark. Alex gazes towards him, and featuring disputational talk, states: "Do not do that, do not start, we are supposed to start!", as he wanted to be the first to begin the challenge with Leo. John does not accept this and states his differing opinion: “Aren't we all supposed to start this on our own computers?". John then withdraws from the mutual gaze and as shown in Fig. 3, begins to delve the toolbox to prepare for the challenge. The toolbox mediated and coordinated the students' joint attention and engagement, John leaning over the box, pushing Alex toward the wall, and leaving Alex with little room to continue his search. They began arguing about the tools required, and it sounds and looks just as if John was entering Alex's territory, even though the boys belong to the same team. Leo maintains his distance and does not get involved in Alex and John's debate in orienting to the challenge, and is still sitting behind them in the front of his computer. Mark also takes a distant stance and stays at the desk John and he have in their use and is thus out of the reach of our video camera. In Fig. 3, Alex is wearing a hat and John is wearing a hoodie. Leo sits behind Alex and Mark is not shown.

Then, Leo encounters some technical problem in trying to open the trailer video for the challenge and asks Alex to help him. Meanwhile, John continues searching the materials for the challenge from the box. Alex drags his chair and moves physically closer to Leo and leans toward his computer, to see better what he is doing, to help him in opening the trailer. At this point, John takes a laser pen out of the box, switches it on, opens the classroom window (the one shown in Fig. 3 behind Leo's head), and starts to point outside the window. Alex finally gets the trailer functioning, and Leo begins to familiarize himself with it. Meanwhile, Alex begins to experiment with a laser pen by moving it in his hands. He seems excited, switches it on, and points toward the teachers' desk, saying to Leo: Alex: "Look, this light reaches so far!'. He then sits down and points to the roof of the computer lab. John still leans on the windowsill using the pointer and redefining its use from carrying out the challenge, to pointing people walking past. By doing this, he leaves Mark to familiarize himself with the instructions, and the two boys do not communicate.

Then, the collaborative interaction of Leo and Alex is temporarily interrupted as a girl, Emilia, from another group, approaches Alex to ask for help finding the right equipment for 


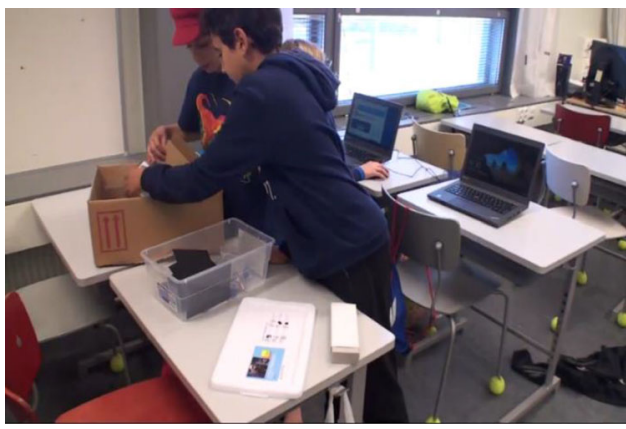

John (to Alex): We already began to do the laser challenge with Mark. I pushed this and then we... (turns and points to Leo's computer screen).

Alex: Do not do that, do not start, we are supposed to start (with Leo). Leo will start by doing this so that we will...

John: Aren't we all supposed to start this in our own computers! We started already (picks up a laser-pen). (Alex nods as a positive response) John: Hey, shouldn't' these be two of these lasers, look. Here is only one now! No, here. Look, I found it!

Alex: No, it's not the right one, we need a different one, this is the same kind (takes another laser pen in his hand)

Alex: Look, this light reaches so far!

Fig. 3 John leans over the toolbox to search for the laser pen and pushes Alex

carrying out a challenge she has selected with her group, sitting at the opposite corner of the computer lab. As Emilia arrives at the desk, Alex starts to point at her face with the laser light on, joking that he is going to shoot her. As shown in Fig. 4, Emilia uses her body and, without words, tries to "defend" herself by covering her face with her hands and smiles. The teacher notices this and says that it is not safe to point at another's eyes with the bright laser light. Then Alex stops and walks with Emilia toward her group. Here, instead of mediating and coordinating joint attention and engagement in carrying out the learning challenge, the students' uses of the laser pens caused temporal fragmentation of the joint activity.

After helping the girls, Alex returns to Leo who had meanwhile collected the requisite tools and is eager to begin building the Laser Defender. Leo then wonders where they should carry out the learning challenge and suggests the computer lab part of the FUSE Studio where they are already. Alex makes an alternative suggestion to move into the corridor, judging the computer room as an unsuitable space for carrying out the laser challenge. Leo appropriates this suggestion, and taking the toolbox and a laptop with them, repositions themselves within the nearby corridor. They position themselves very close to one another, sit down in the corridor, and engage with interpreting the instructions of the learning challenge, and using cumulative talk, by repeating the instructions. They also begin to envision, plan and ideate the next steps of the process. Leo offers information to Alex by stating: "It (the Laser Defender) needs to be one meter long". As we can see from Fig. 5, Leo,

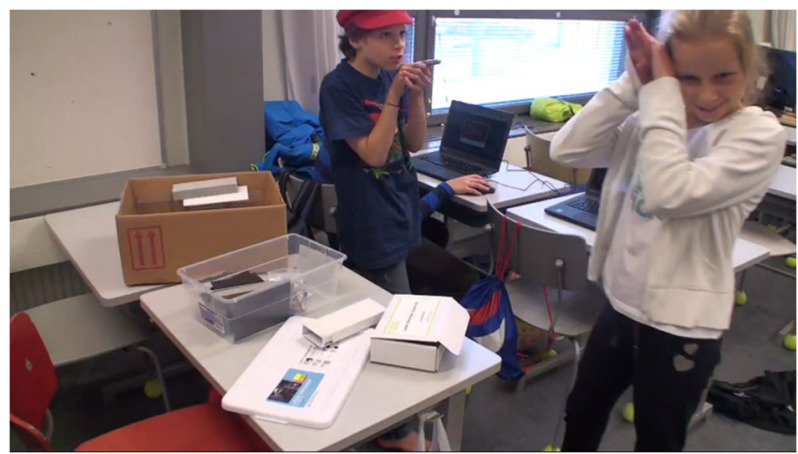

Fig. 4 Alex points at Emilia's face with the laser pen, and she tries to defend and smiles 


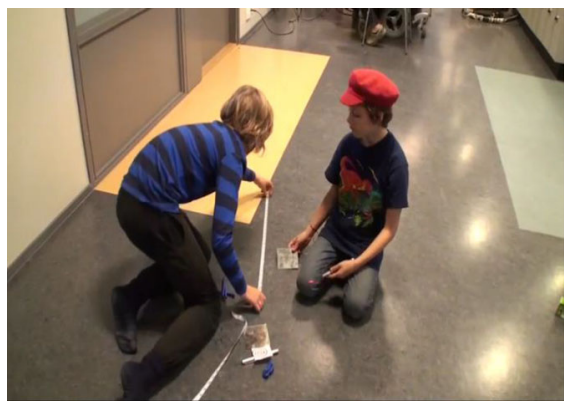

Leo: Alex, where should we go to do this? Shall we do it here? (in the lab) Alex: We are getting close to having all the equipment we need. Let's not do it here, let's do it in the corridor! Leo: Okay, let's go there. (Then, both boys stand up and collect the rest of the tools and move to the corridor to build the Laser Defender. In the corridor, both boys sit on the floor very close together). Leo: It (the Laser Defender) needs to be one meter long (Leo places a measuring tape).

Fig. 5 Leo places a measuring tape on the floor and Alex holds a mirror, to proceed with the challenge

who is wearing a striped jumper, places a measuring tape on the floor, and Alex (wearing the hat) holds one of the mirrors to begin with the challenge.

A video camera is placed in the corridor to film them. Alex suddenly points to the camera's lens with the laser pen, temporarily turning the boys' attention away from making the Laser Defender. While playing with the laser pen and the camera, both boys smile and laugh as Alex's light is brightly reflected from the camera's lens, as shown in Fig. 6. Leo also tries to point to the camera with his laser pen but realizes that it does not work, and guesses its battery has run out. He thus returns to the computer lab to get new batteries. The new battery first flips from his hand and lands on the floor, but he then gets the laser pen functioning, and the boys continue playing with the laser pens and laughing. Then, Alex repositions himself toward the measuring tape, gazes down, and draws Leo's attention by calling his name in a loud voice: "Leo! Come and look!", and Leo turns toward Alex, and their joint attention returns to the challenge.

When externalizing their knowledge creation of the Laser Defender (i.e. the knowledge object), Leo and Alex do not often engage in gazing at one another. Instead, their joint attention (talk and embodied actions) is strictly focused on the hands-on materials, for example Alex asking Leo's opinion: "How should the mirror be then?" And Leo, having familiarized himself with the instructions, constructs knowledge via cumulative talk gained from this, and tries to negotiate the concretizing of the knowledge object with Alex by saying: "I think we must use two of these mirrors to get the light to hit the target". Then, Alex starts pointing with

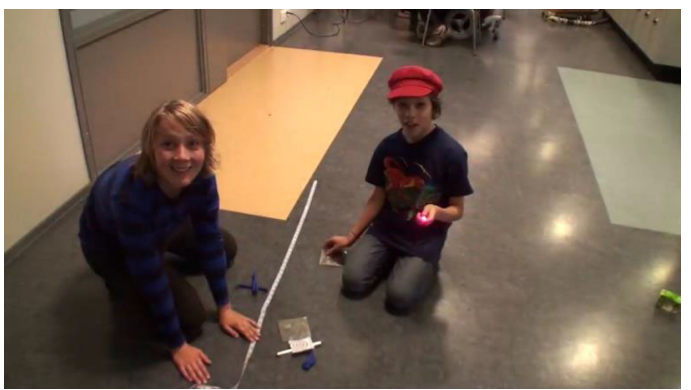

Leo: (pointing to the video camera) It looks so funny! Look how bright it (light) reflects! Alex: Is someone in there (inside the camera)? (joking and the boys laugh and play silently).

Alex: (draws Leo's attention) Leo! Come and look. Could you hold this mirror? How should the mirror be placed then? Leo: I think we must use two of these mirrors to get the light to hit the target. There needs to be two (mirrors).

Alex: Do not do that! Put that away, we don't need that! (the mirror Leo has).

Fig. 6 Boys having fun pointing to the video camera's lens with their laser pens 
his laser pen toward the wall, as we can see in Fig. 7. Constructing knowledge via disputational talk, Alex then disagrees and says to Leo, who has another mirror in his hand: "Do not do that! Put that away, we don't need that!". By stating where they should place a mirror, and by disregarding the option offered by Leo, Alex tries, however, to further concretize the knowledge object. The atmosphere seems quite tense and Leo disagrees, with a critical tone in his voice, using disputational talk: "There should be two mirrors, not just one!", demonstrating by holding the second mirror in his right hand. As illustrated in Fig. 7, Alex continues pointing to the wall with the laser pen. Suddenly, Leo then looks away from Alex, and temporarily, physically withdraws from the challenge by walking away from the corridor, back to the to the computer lab without saying anything more (see Fig. 7).

As we can see from Fig. 7, Alex gazes towards Leo but does not say anything to him as he walks away. He keeps on placing the mirrors in different positions, trying to concretize the epistemic object (the security system using lasers and mirrors). It looks at that point as if their collaborative interaction will not continue, however, after a while Leo returns. At this point, no words are exchanged, and the boys silently continue placing the mirror in a range of positions and directing the laser pen multiple times, via trial and error. After a while, they constructively engage with each other's opinions, contributing to knowledge creation via exploratory talk, Alex first demonstrates with his hand his novel idea on how the light would move, and suggests: "We should try this out, then we would have a laser which goes there". In practice, he then explores this new option of placing the two mirrors and says with a confident voice: "Let's place this here, and this here, I really like this!", appropriating and expanding Leo's original idea of including the two mirrors. By doing this, Alex also distills away his earlier idea, unsuitable to concretize the knowledge object. Leo first agrees, and they stand in silence for a while viewing what Alex invented.

Some students then walk past and disrupt their work. However, they stay focused on the task. Yet, Leo is still not satisfied, again disagrees, and uses disputational talk to further contest Alex. He suggests a modified approach, of his own invention, relating to positioning the mirrors, stating that: "No, I do not think this is the way, I have an idea!". He silently demonstrates this to Alex by placing the mirrors in different positions to further concretize

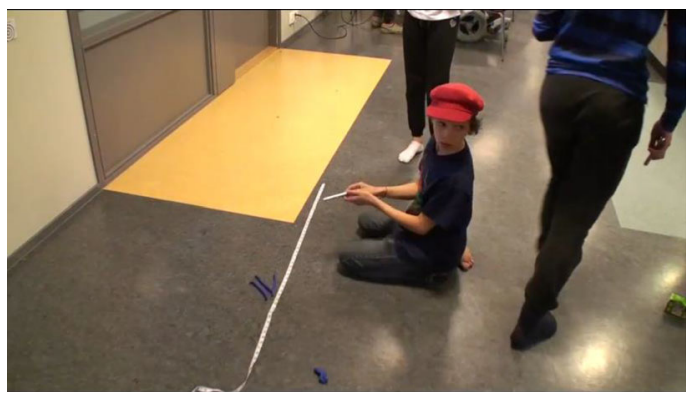

Leo: There should be two mirrors, not just one! (Leo walks away and after a while comes back) Leo: Let's place this here, and that there and then. I'm trying really hard to do this! Place it there, we need to reflect it from the mirror. We cannot place it here!

Alex: I know now, like this. We should try this out, then we would have a laser which goes there (demonstrates). Let's place this here, and this here, I really like this! (the boys view Alex's work).

Leo: No, I do not think this is the way, I have an idea! (demonstrates). Let's put one here, the other there, there is one and it reflects here and the other there, does this suit you?

Alex: Yes. (Alex nods and moves close to Leo to adjust the mirrors).

Fig. 7 Alex points to the wall and Leo withdraws from doing the Laser Defender challenge 
the shared epistemic object. Alex then appropriates by simply replying: "Yes!", accompanied by his use of his body to expresses shared understanding by nodding to Leo. Alex joins Leo in further testing with the laser pens, and soon the Laser Defender starts functioning, and the boys successfully complete the challenge.

Thereafter, their knowledge is made publicly accountable as they then introduce their laser defender to their peers John and Mark. John and Mark had also carried out the same challenge, and completed it successfully, but through a different design and making process in the FUSE Studio space. Alex and Leo invite them to break in, to try to steal their valuable "treasure". While they are doing this, Emilia, who Alex had helped earlier, and her group member Linnea enter the corridor to view the Laser Defender created by Alex and Leo. All the boys then turn their attention to the girls, and away from stealing the treasure, and start playing with the video camera, posing and making funny faces. Alex throws his cap and rolls on the floor, and (without words) points to Linnea with the laser pen, who as shown in Fig. 8, tries to defend herself by holding her left hand as a shield. Both laugh. Then, John and Mark leave, and Linnea, who is still sitting on the floor, picks up the laser pen and leans over the Laser Defender, expanding the usage of the knowledge object from the established group, trying to steal the treasure while Leo and Alex are viewing. Lastly, Leo takes a photograph of the boys' accomplishment.

In this episode, Alex behaves in a commanding manner toward Leo. Nevertheless, together he and Leo collaboratively interacted and equally contributed to solve the learning challenge of creating a laser beam security system to protect a valuable "treasure". Cumulative, disputational, and exploratory types of talk were used as mediational means, together with multiple material artifacts, such as the toolbox, measuring tape, mirrors, laser pens and the video camera. All these served as important mediators, enhancing the externalization and the internalization of knowledge as well as the enactment of knowledge practices during their interaction. In this episode, the corridor as a physical space played an especially pivotal role in mediating the students' interactions and knowledge practices, and it can be viewed as an improvised spatial expansion for the makerspace, providing opportunities for the students' embodied actions and the extension of the given instructions. Further, the corridor importantly allowed for the creation and testing of innovative solutions, as well as the concretization of the shared epistemic object. Despite the boys' frequent use of disputational talk, combined with strong embodied actions, such as pushing one another and withdrawing from the situation, the boys successfully solved the laser challenge. Further, the disruptions, although temporarily fragmenting their maker work, served important social functions, such as gaining the girls'

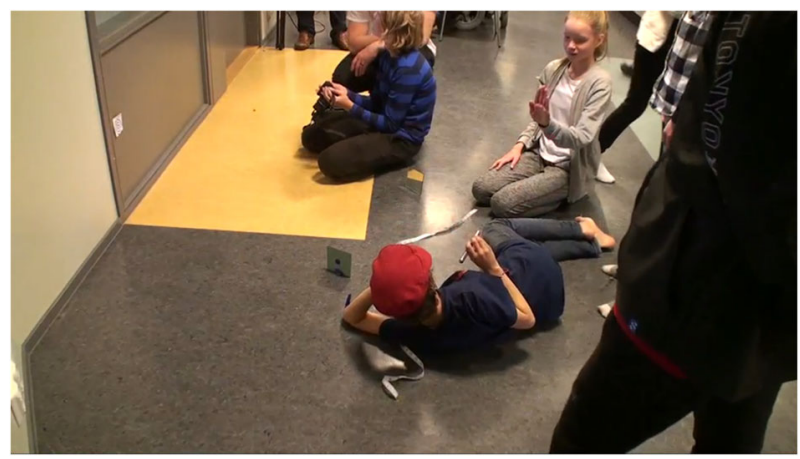

Fig. 8 Alex points at Linnea with the laser pen, who holds her hand as a shield 
attention and having fun with peers, and the boys always managed to return to their joint attention on the challenge.

\section{Episode 2: Pursuing the keychain challenge in the classroom part of the FUSE studio}

Also in this episode, discourse, digital and other hands-on materials, embodied actions, such as gestures and postures, and the physical arrangement mediated the students' collaborative knowledge practices (i.e. orienting to, interpreting, concretizing and expanding knowledge), generating joint attention and leading to extending the given instructions, and the successful and creative completion of the learning challenge. Here, we focus on an episode in which a group of girls had a member among them who was familiar with the challenge and who, when asked by her peers, took the responsibility for coordinating the other three girls' making process. Furthermore, in this episode the girls did not make use of the surrounding space but remained in the classroom part of the FUSE Studio for the whole time, sitting around a desk. In this space, their interaction involved a rich constellation of embodied actions, which were first carried out by the member holding knowledge on the challenge, but later by all the other members of this group, to demonstrate, coordinate and support the other group members' work, to creatively work with their hands, leading to the creation of unique keychains.

Four girls (pseudonymized as) Nellie, Emmi, Sara and Nora begin collectively orienting themselves to carry out a learning challenge as a group. For this, they position themselves in the part of the FUSE Studio that is arranged as a more regular classroom, having a single large table around which they all sit next to each other. They jointly decided to work on the FUSE challenge called the "Keychain Challenge", in which the students design and 3D print a keychain with their name or custom message. (For more information see: www.fusestudio.net/challenges). Each of the girls has her own laptop on the table, and they sit closely beside one another as they share two computer screens to design keychains by using the FUSE computer program. Then, Emmi, who is familiar with the challenge, walks into the next room, the computer lab, to get the hands-on materials she wants the girls to use in their work on their keychains.

The episode in our focus here begins as Sara tries to connect the parts of the keychain without succeeding and soon asks for help from Emmi. This situation is illustrated in Fig. 9 in which Emmi is the third girl from the left and Sara is sitting second from the left wearing a black cardigan. Emmi says to Sara: I'm good at this! I have viewed this challenge and I understand this", sounding quite self-satisfied, but we can see from the way in which Emmi engages her body in Sara's making activity by grasping Sara's hand with a smile and friendly gaze (in Fig. 9), that she eagerly and genuinely wants to help her. We do not know whether Emmi has, as a matter of fact, carried out this particular learning challenge before, as she says she has viewed it, which may refer to merely viewing the instructions or the work of other students. However, here, Sara depends on Emmi, and also the other two peers grant her the responsibility for instructing them as well. Nellie is sitting on the far left and Nora on the far right (in Fig. 9). They each take a rather individual stance, trying to familiarize themselves further with the instructions by looking at the "My Challenges" interface on their own respective computer screens. This ends very soon as the girls turn their attention to jointly following what Emmi is doing with Sara.

Then, Emmi begins orienting all the others to the task by offering information and demonstrating with her hands how to make a special keychain by sewing beads of different 


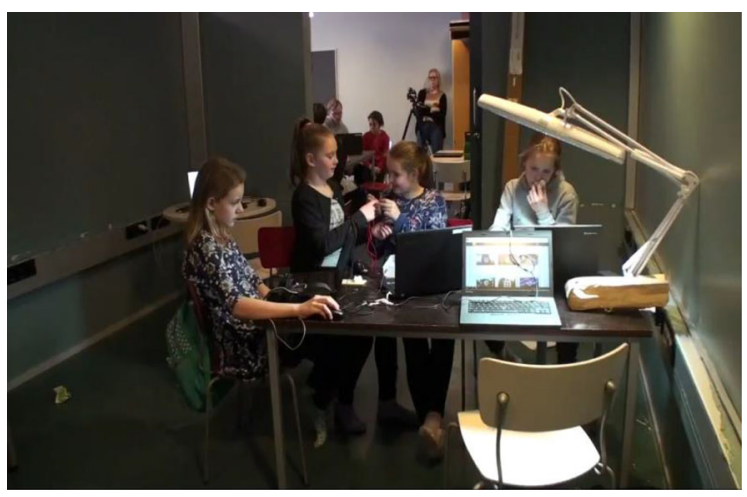

Sara (to Emmi): I am totally lost now. How can we proceed from here? Tell us.

Emmi: I'm good at this! I have viewed this challenge and I understand this! (begins to unpack the toolbox). Let me help you! Nellie: Are we doing this in the right way? What are these purple parts? How does this go?

Sara: How can I make this smaller and at the same time wider? Please, help me. I would really like to do this. Could I do something like that?

Fig. 9 Sara struggles and Emmi smiles and offers help

colors to it. Her existing knowledge, embodied actions, as well as the thick thread and the beads, began to mediate and coordinate the four girls' joint attention and engagement. To interpret Emmi's demonstration, Sara then starts constructing knowledge via cumulative talk by repeating by heart and reiterating by embodied actions what she had demonstrated to her. For this, she quickly takes the keychain from Emmi's hands, visioning, planning and ideating the next steps in her making process: "Could I do something like that?". Emmi confirms by nodding to her that she has understood correctly. Thereafter, Sara, with a happy look on her face, continues exploring, stitching and connecting the parts by herself, beginning to concretize the shared epistemic object (i.e. designing and producing a customized keychain).

Their making process then stops for a while as the girls begin to discuss their pets, especially about a rabbit Sara had and that had recently died. The girls reminisce about the rabbit and also make jokes about it and how difficult it is to select a name for pets. Then, their making activity continues as Nellie draws their attention back to the task by asking a question: Are we doing this in the right way?, combined with a long gaze toward Emmi, as a way of expressing a desire for her to assess their progress and also to support her. After this, Sara tries to connect the parts of the keychain and is moving back-and-forth (by embodied actions), but then again begins to struggle and asks for further help from Emmi. Then, Emmi begins the joint interpretation of knowledge, and she looks down at Sara's hands, and then glances at the laptop in front of her. She frowns, and confidently begins elaborating to all girls how the parts of the chain need to be connected, in fact raising the difficulty of the learning challenge, and extending the instructions of the FUSE program.

The making process then proceeds so that Sara states to Emmi: "Oh dear, this is so difficult! This hurts my hands a bit". As shown in Fig. 10, the two girls withdraw from the group activity by taking an embodied action of leaning forward and directing their joint attention (as a pair) to supporting Sara's sewing and the concretization of the shared knowledge object. When verbally externalizing her knowledge to Sara, Emmi simultaneously demonstrates to her the procedure by sewing and connecting some parts of her own keychain she has in her hands. Again, Sara is trying to interpret this by replicating Emmi's actions with her hands, sewing black beads to decorate her keychain. Yet, Sara finds it difficult to proceed with attaching the beads. At this point, Nellie is also carefully paying attention to Emmi's demonstration, and Nora has stood up to see it more closely. After the girls view Emmi's actions for some time, we can see (in Fig. 10) how Nellie gazes at Nora (standing on the righthand side of Fig. 10), and raises her thumb up, as if a sign of appropriation and understanding Emmi's instructions, to 


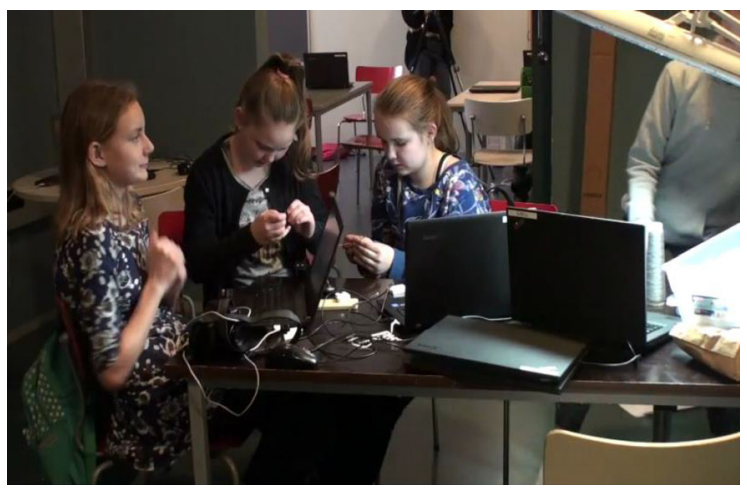

Sara: I wonder how this needs to be done (tries with her hands). Oh dear, this is so difficult! This hurts my hands a bit. This comes off really easily (tries out). Sara: How can I do this?

Emmi: Sure, I can help, I know this (leans towards Sara). Please take the black one. Yes, good! You first place these things together. Then, take that black bead next because you need it to hold this together (Sara takes a bead from Emmi's hand).

Fig. 10 Emmi and Sara direct their joint attention to their hands to support Sara, and Nellie raises her thumb to Nora

which Nora nods, as a sign of appropriation. It can also be seen as an embodied act of collaborative distillation. Nellie sets aside some of the options and solutions she and Nora had so far tried out, reinforcing Nellie and Nora's joint decision to proceed with the making activity according to Emmi's instructions.

After a while, Sara is again struggling, and seeking for Emmi's help, who tries to strengthen her confidence and simultaneously begins to give her more elaborate advice about creating the keychain. In this, first by praising Sara by saying: "Yes, good!, and then with a confident gaze, taking the role as an expert, Emmi further externalizes her tacit knowledge and experience to Sara, guiding her: "Then, take that black bead next because you need it to hold this together". Emmi states that it needs to be a different black item, and hands the necessary one to Sara, who takes it from Emmi's hand. She then supports her with encouraging words, and exemplifies exploratory talk by suggesting: "Let's not think about if it's difficult or not, we can just try it and see how it goes. It's fun". As demonstrated in Fig. 11, all girls including Sara then smile, appropriating Emmi's view. This is an important turning point in Sara's progress with the challenge, as thereafter, holding the bead in front of Emmi, she smiles and constructively engages with her opinion and reasoning. She says: "Here is the black one, I think this should work", expressing that she had understood the instructions and gained some confidence via the other girls (verbal and embodied) support.

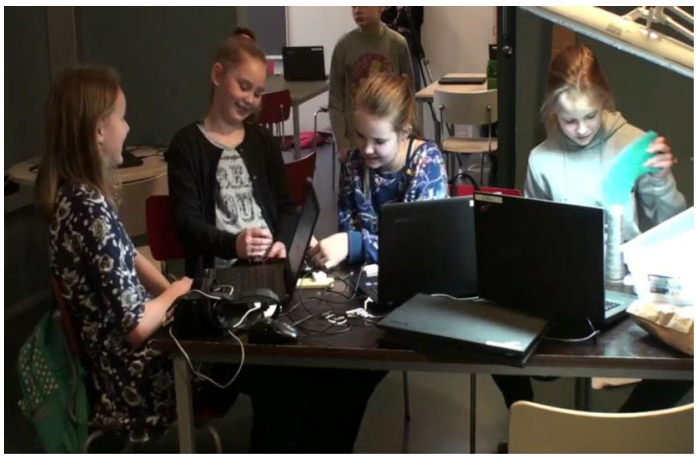

Sara (to Emmi): How can I do this? Look how this looks?

Emmi: Let's not think about if it's difficult or not, we can just try it and see how it goes. It's fun! (all of the girls smile).

Sara: OK. Here is the black one, I think this should work.

(Then, she accidently drops her computer mouse on the floor). Sara:

I think this mouse was already a little broken.

Fig. 11 Emmi suggests not think about the difficulty of the challenge; all smile 
The tools and embodied actions mediated and coordinated the students' joint attention and engagement, and the four girls had collected information, concretized knowledge, and had developed a shared understanding of the artifact they were creating. Their making activity then is temporarily disrupted as Sara drops her computer mouse on the floor. She picks it up and starts trying to see whether it is broken, and the other girls silently wait for her, and the mouse still functions. Then the girls direct their attention back to the task, and Emmi is still looking over Sara's work and providing her with support and guidance when needed. Soon after, Emmi finalizes her own keychain, raises her head up, and starts to giggle. These are all signs of a positive atmosphere. Sara smiles back to her and then puts down the bead from her right hand, holding the new, squared black object in her left hand, and starts to insert a cord to run through it. At this point, Nellie and Nora, also supported by Emmi's instructions and by one another, successfully complete their keychains. Viewing Sara's work, leaning closer to her, and pointing at her hand with the black bead, Emmi then explains: "You need to bind it then in a hook-like manner". Sara adds her own reasoning by responding with a question: "Like that?", demonstrating that she had understood and simultaneously changing her making process, and Emmi replies: "No, not like that, like this". This is not viewed as disputational talk, but more as an effort to negotiate the concretizing of the knowledge object, as Emmi is responding with a smile on her face. Appropriating Emmi's idea Sara then adjusts the position of her hand, leading to the successful completion of the keychain, and joyfully shouts: "Oh, $m y$ god, look, I managed to do it!' As illustrated in Fig. 12, Nora turns her attention to Sara and Nellie raises her hands to celebrate her success and all girls smile.

In this episode, Emmi, who had more accumulated knowledge of the challenge and in stitching, played a pivotal role in sharing her knowledge via talk and bodily movements, such as touch and demonstration, and use of the thick thread and the beads. Through this contribution, the challenge became understandable to the others, and concretized into a shared epistemic artifact. Especially, Sara's questions to Emmi promoted the externalization of Emmi's knowledge, cumulative talk, and the enactment of the knowledge practices. Emmi's creative expansion of the instructions generated exploratory talk and embodied actions leading to a special design (inclusion of beads) of the keychains, simultaneously increasing the difficulty of the learning challenge, yet also taking full responsibility for guiding others. However, even if Sara often struggled, in this episode, we did not witness disputational talk. Instead, the atmosphere was positive and supportive, and all successfully completed the challenge. Even though Emmi mostly instructed the others, they worked collaboratively as she was also discovering new things. The other three girls also, mainly by embodied actions

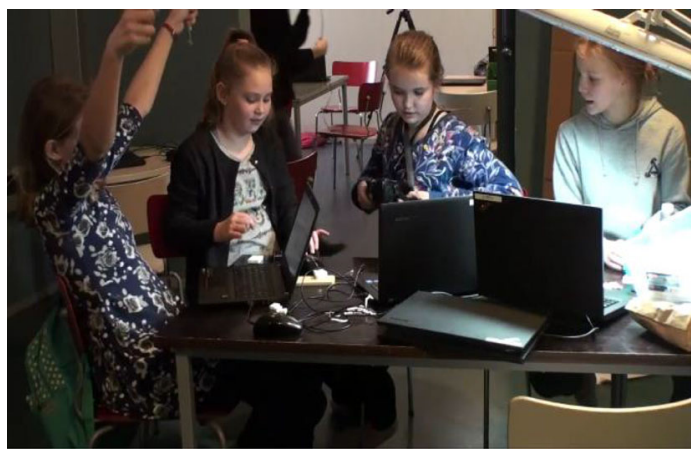

Emmi: No, no, not like that! Like this, from there (demonstrates). Then, you need to do like that. You need to bind it then in a hook-like manner.

Sara: Oh, my god, look, I managed to do it! Wow!!

Nellie: Go and get the camera, so that we can take a photo of this!

Fig. 12 Nellie raises her hands to celebrate Sara's success 
introduced new ideas to the joint activity, contributed to the concretization of the artifacts. Nora and Nellie mostly worked independently and remained mostly silent. However, with their embodied actions they actively took part in the inquiry, collaborative interaction process, and knowledge practices. In this episode, the girls did not comment on the presence of the video camera. They stayed in their selected space, and did not express an intention to reposition themselves within the room, or to move elsewhere during the session, except for Emmi in the beginning, collecting materials from the space next door.

\section{Episode 3: Building a roller coaster in the computer lab}

As in the two previous episodes, in this case discourse, digital and other "hands on" materials, embodied actions, and the physical arrangements mediated the students' collaborative knowledge practices (i.e. orienting to, interpreting, concretizing and expanding knowledge), leading to the successful completion of the learning challenge. Also, in this example, the students (the same boys as in the first example) made use of the FUSE Studio space and its materials in creative ways, for instance, by standing on the cupboard in order to coordinate their work in the computer lab. Also, in this episode, the learning challenge was new to the boys. They critically but mostly constructively engaged with each other's ideas, and made expansive uses of the tools they'd been given. Their work included a rich constellation of embodied actions and acts of trial and error, pivotal for the boy's joint attention as they progressed with the challenge. Also, in this episode, the boys' critical commenting and joint exploration led to the creative expansion of the instructions provided by the FUSE Studio computer program.

Four boys, Leo, Alex, John and Mark decided to work as a group again, this time in the computer lab part of the FUSE Studio on a "Coaster Boss" learning challenge. In this challenge, a roller coaster is built, and a marble ball must pass through the track at a certain speed and under certain conditions. (For more information, see: www.fusestudio.net/ challenges). To orient themselves to the challenge, the boys select materials for the challenge from the cupboard without looking at the instructions on the computer screen and place the materials into a carboard box. As the boys decide to build two roller coasters, John and Mark, belonging to this group, worked with the same challenge building their roller coaster in the opposite corner of the computer lab, and did not communicate with Leo and Alex until the end of the FUSE Studio session. In this episode, we focus on presenting the work of Leo and Alex.

When positioning themselves in the space, to carry out the challenge, Alex and Leo place a computer on the floor, and they focus their joint attention in viewing the instructions from the "My Challenges" interface. Alex is reflecting on the instructions with Leo and they soon realize that for the ball to roll fast enough, the roller coaster needs to begin from as high as possible in the room.

Taking a collaborative stance, they decide that Alex should climb on the low cupboards, behind the teacher's desk. Leo hands him tape and foam strips. Leo begins envisioning the roller coaster and interpreting the instructions by suggesting they slice the tape into pieces of a certain length, long enough to keep the coaster steady, to start from the wall. For this Alex asks for tape in a commanding voice. As shown in Fig. 13, Leo is wearing a striped jumper and gazes towards Alex (whose face does not show due to the positioning of the camera) and asks his opinion: "What size do you need?". Alex bodily offers him information, by showing the size with his fingers. Then Leo, via disputational talk, begins to question the way Alex is 


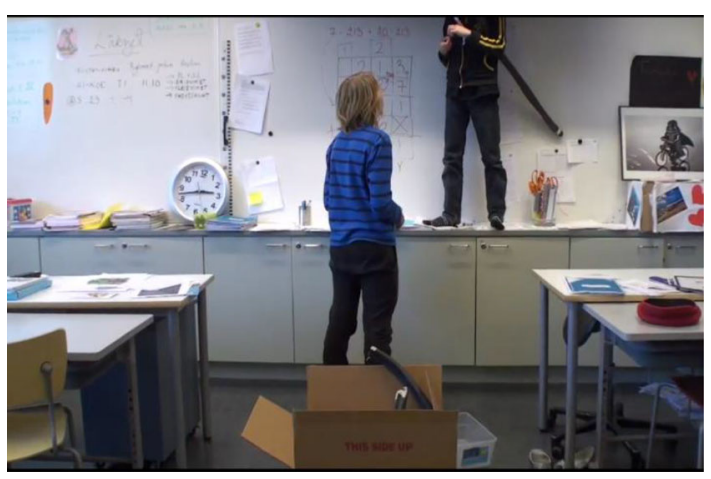

Alex: Hand me more of that tape and tubes (foam strips) (in a commanding voice).

Leo: What size do you need? (Alex replies by showing withhis fingers). Leo: OK, here is the tape. But hey, that part does not go like that. You need to put it there! I'm sure, it will not stay put if you place it like that. If we do it like this (walks to the toolbox and gets two more foam strips form the box) Leo: I'm starting to create a track from this. But the ball will not go like that! (walks again to the tool-box and gets two more foam strips form the box).

Fig. 13 Leo hands Alex, who stands on the cupboard, tape and other tools

attaching the foam strip to the wall: "OK, here is the tape. But hey, that part does not go like that. I'm sure, it will not stay put if you place it like that". To which Alex firmly replies that he thinks it will stay put, and continues working on the challenge alone, iterating and repeating some earlier phases of the process.

As Leo disagrees, Alex jumps from the cupboard to the floor to construct jointly a more solid tube with Leo. The boys work together using tape to attach the strip foams together. Alex then climbs back on the cupboard to hold the rollercoaster in a certain position so that Leo can add parts to it. However, Alex does not say anything but still seems not completely satisfied about how the coaster is positioned. He jumps from the cupboard to the nearby desk to reposition it. He keeps sitting on the table for quite a while trying to adjust the coaster's position. Then, both boys enthusiastically move to see how the marble ball moves along the tube and try to roll it for the first time. For this, Alex jumps from sitting on the desk to stand again on the teacher's cupboard. Suddenly, the ball gets stuck in the tube, making Leo question Alex's way of adjusting the position of the tube. Then, Leo takes over adjusting the tube, which Alex agrees to, and as suggested by Leo, cuts some foam from the high end of the tube. Then, Alex suggests to Leo: "Now, let's test it with the ball, to make this coaster really great!", exemplifying exploratory talk and trying to create a satisfying shared epistemic artifact. Leo nods and appropriates his suggestion. The boys test the coaster to see whether it works. When carrying out the test ride, the marble ball, however, rolls too fast and bounces away from the boys, under a desk, and Leo seeks it, with Alex holding the roller coaster that they had created so far, as shown in Fig. 14. The boys looked disappointed (from their facial expressions) and decided to revise their plan and the epistemic object in progress, in order to jointly appropriate it and to make it function properly.

As Leo finds the marble ball, the boys then re-direct their attention to making adjustments to the coaster, and decide to reposition it, to make the ball roll slower, not to bounce off the track. Leo continues reasoning and adjusting the foam strips by adding tape, to which Alex loudly exclaims by disputational talk: "No, no, no, do not do that!" and disregards Leo's further suggestion about adding a whole new foam strip to the coaster. Alex then further commands Leo to provide him with some materials from the floor and scissors. Then, Alex very carefully adds a small piece to the end of the tunnel, and with this embodied action distillates Leo's idea of using the longer piece of the foam strip. Alex then shares his existing knowledge and suggests they create a loop to make the ball roll slower. As we can witness 


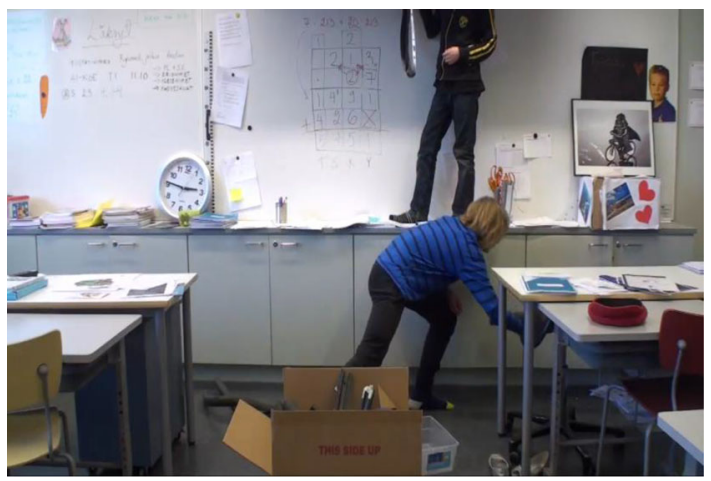

Alex: Now, let's test it with the ball, to make this coaster really great! (Leo hands Alex the ball and he puts it into the tube and it rolls). Leo: Here it comes (the ball) (the boys silently gaze at the tube). Leo: Now, this was a real fast speed! There it went! This was far too fast! The ball drops from there (points with his finger) as it bounces off. We need one more long tube part and more tape to make this work (Leo starts making adjustments)

Alex: No, no, no, do not do that! Let me add some additional strengthening to the tube. Hand me that small piece and hand me the scissors (Leo does this but disagrees). Leo: The tube is not long enough; we need to make it a bit longer. What if we tried to do it like this? (demonstrates with his hands).

Fig. 14 The marble ball rolls far too fast and bounces under the desk and Leo crawls to search for it

from Fig. 15, Alex then smiles, and verbally explains and demonstrates with embodied actions his idea of the loop. In Fig. 15, we can see how he uses his body to makes a circular movement with his left hand, to demonstrate a loop. Leo carefully gazes toward him and follows his demonstration (see Fig. 15) on how to proceed to make the coaster function correctly. Having observed this for a while, Leo negotiates with Alex on the positioning of the loop. They adjust it a little, and then he appropriates Alex's idea by confirming: "Yes, you are right, it goes really handy there, just like that", featuring shared understanding of the knowledge object in the making. It also exemplifies collaborative distillation, as Leo and Alex are diverting away options, which did not aid their progress. To proceed, the boys then decide to switch roles and Leo adjusts the tube by adding tape to attach it more firmly to the table, and Alex holds the foam strip from where they are creating the loop. During this collaborative interaction, joint attention, mutual engagement and decision making, the knowledge object (the roller coaster through which a marble ball rolls at a certain speed), further concretizes. Both boys smile and seem satisfied by the way their work is proceeding.

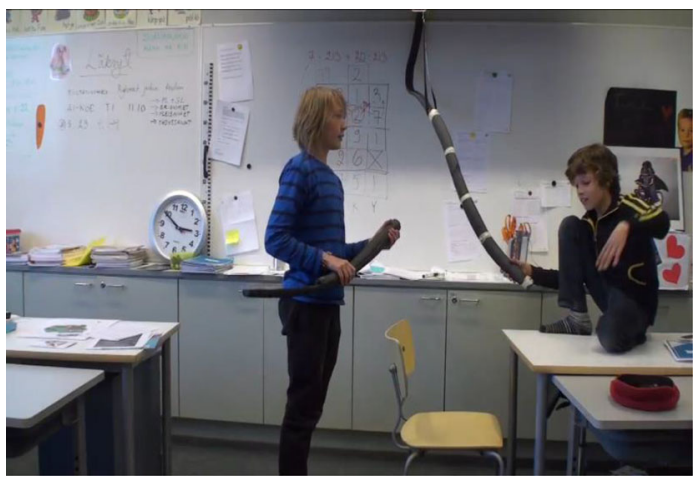

Alex: It goes like this, we need to attach these together here, and place this part in between, like that. Now, it will definitely stay put! We should create a loop here to slow the speed down a bit. Is that ok? (demonstrates this by making circles with his left arm and holding the tube in his other hand). (...)

Leo: Ok, after you tape, it will stay like that. Yes, you are right, it goes really handy there, just like that!

Alex: What if we place it here? (points to the desk he sits on). Alex: Take the tube, not that, the longer one. Can you hold this? Not like that, like this (Leo holds the additional strip foam and Alex uses tape to attach it to the existing tube).

Fig. 15 Alex smiles and demonstrates, by making circles with his hand, his idea of creating a loop 
Then, the teacher comes along, telling the boys that the session will soon end. The boys begin to hurry to finish their roller coaster, as Alex had just begun adjusting the tube. Both boys wanted to test whether this would make the marble ball roll at the right speed. As shown in Fig. 16, Leo inserts the ball into the roller coaster, and Alex gazes upwards in order to observe. Before doing this, Leo uses his knowledge, accumulated from the first trial of the coaster (including multiple instances of trial and error), and places a plastic box at the end of the tube, to ensure that the ball will not bounce onto the floor and break. After some further reasoning, exploring and adjusting by Alex and Leo to improve the coaster, and Alex jumping back and forth from the desk to stand on the cupboard, the roller coaster begins to work as they wanted.

Leo and Alex then made their epistemic object (the roller coaster in which the ball rolls at a certain speed) publicly accountable by inviting their peers, John and Mark, to roll the ball with them on the coaster. They do this multiple times and are having fun. By doing so, they refuse the teacher's instruction not to continue their maker work. Soon, the other teacher present in the makerspace (in a strict tone of voice) tells them to stop and to leave the classroom, as they had already stayed longer than allowed. Then, the boys physically turn their backs to the teacher, and avoid looking at him, and do not verbally respond to him. As the teacher repeatedly commands them, they finally begin tearing down the coaster, and while doing it, they suddenly transform their epistemic object into two "weapons" with which they start playfighting with one another by using the long foam pieces as swords. As illustrated in Fig. 17, Alex first raises his sword and Leo holds his one in his hand and responds by hitting Alex's sword, while Mark and John are watching. Disregarding the teacher's command, all four boys then start playing with the video camera, filming themselves, and leave the computer lab after the other students.

In this episode, as in our first example, Leo and Alex collaboratively interact and challenge one another by expressing differing opinions. As in the first example, this is, however, mostly constructive and, in this episode, we witnessed less disputational talk than in the first example. In concretizing their knowledge object, the roller coaster, the boys moved back and forth in their process. They searched for solutions to the problems included in the learning challenge, leading to the successful completion of the challenge. The challenge was new to the boys and, as in the first example, both actively contributed to the making and problem-solving activity. Also, though Alex had a tendency to command Leo, we were able to witness from his nonverbal communication that he respected Leo as a collaborator. They used a rich constellation of embodied actions, as well as the materials and the space itself by their standing and sitting on the cupboard and the desk, to enhance the enactment of their knowledge practices and

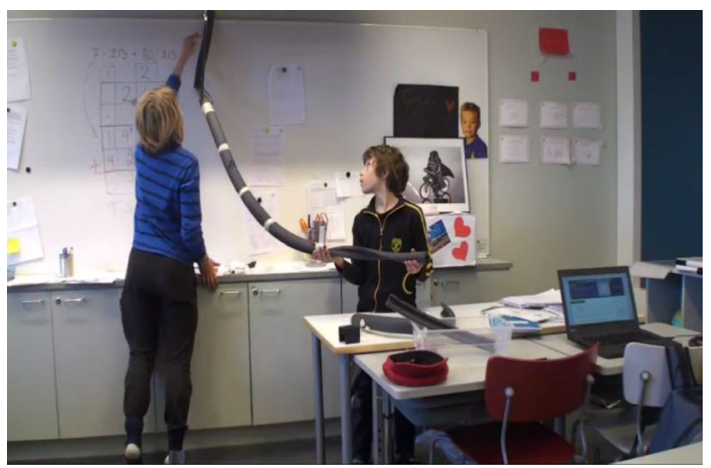

Teacher: Our time will soon end and then you need to clean up. It's time to assemble things (the boys continue to work).

Leo: Hurry, hurry, we are running out of time! Now, now! (after some adjustments they test the tube ones more).

Alex: Wow, now it works!!

Leo: Yippee! We made it!! (John and Mark come closer to view).

Teacher: You coaster bosses, you must wrap up now!

Fig. 16 Leo enters the ball to the coaster and Alex views 


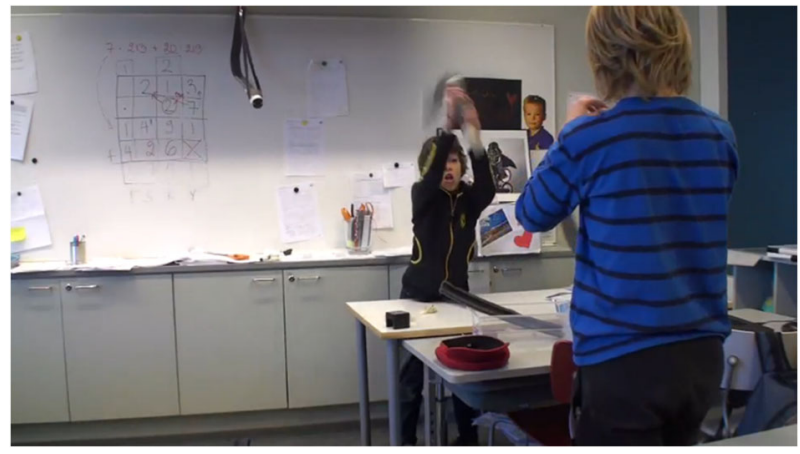

Fig. 17 Alex raising his "sword" to playfight with Leo

creativity. In contrast to the first example, the boys did not express an intention to reposition themselves in the space, or to move elsewhere during the session. In this episode, when they were close to completing the challenge, the teacher came along and asked them to tear down their roller coaster as the session was ending. Consequently, they stayed in their selected space and when rejecting the teacher's commands, expanded their usage of the shared epistemic object to have fun with one another and their peers.

\section{Discussion and conclusions}

School-based makerspaces have not yet received much research attention when it comes to understanding students' collaborative knowledge practices within these novel learning environments. In this study, with the aim of furthering the educational potential of technology-rich learning environments, to support students' knowledge creation and learning, we investigated the students' knowledge practices through a multimodal lens, directing our attention to discourse and material, spatial and embodied modalities mediating students' design and making activities. This led us to identifying four types of student knowledge practices, namely orienting to, interpreting, concretizing and expanding knowledge, guiding and facilitating the students' learning activity in the FUSE Studio makerspace.

Our findings add to the existing research on makerspaces, as well as collaboration within them, by making connections between different types of students' talk (see Mercer et al. 1999; Mercer 2005, also Mercer 2019) and their collaborative knowledge practices. When the students were carrying out the STEAM design challenges and enacting the knowledge practice of orienting to knowledge, they typically applied cumulative talk, and often relied on the FUSE Studio computer program to follow the instructions it provided. Yet, as an extension to orienting they used embodied actions such as moving physically towards one another and began searching for mediating means/tools to support their inquiry, such as foam rubber, a marble, tape and scissors, and 3D printers. They also sought alternative spaces and physical arrangements to better serve their making activities, depending on the challenge.

The interacting students held different knowledge sources, and some were less and some more knowledgeable than others, creating challenges and tensions in collective knowledge creation (see Ludvigsen 2012). However, the more knowledgeable students played a crucial role in guiding their peers, and the groups we studied did not typically call their teachers to help them. The interpreting of the knowledge in the pre-given instructions, and one another's 
existing knowledge often involved the students' construction of common knowledge via cumulative talk, in other words, by accumulation and repetition of the instructions provided by the computer program. In their interpreting we can also witness an increase in the students' usage of short utterances and instances of assertion and counter-assertion, competing arguments and constructive criticism, in other words disputational talk. It also included some critical but constructive engagement in hearing each other's opinions, statements and suggestions, accompanied by embodied acts and gestures, such as gaze, demonstration, and physical withdrawal from proceeding with the challenge (see also Mondada 2018). With language, such gestures in the students' interaction provide an informative source of evidence regarding the students' knowledge, and the nature of maker work (see also Koskinen et al. 2015). Our analysis thus contributes to the understanding of human gestures as tied to the physical, social and cultural properties of the learning environment (also Goodwin 2003; Streeck et al. 2011).

When carrying out the STEAM learning challenges and enacting the knowledge practice of concretizing their visions, ideas and plans into epistemic objects and material artifacts, the students' talk often exemplified features of disputational talk, as the students disagreed and contested one another when working with the available conceptual, material and spatial resources, and in creating knowledge objects and artifacts. We were also able to witness exploratory talk, in which the students made use of a rich variety of available verbal and embodied resources, and for example collaboratively expanded the instructions and redefined the use of certain tools (also Baker et al. 1999), to produce artifacts meaningful to them. The students enactment of the knowledge practice named expanding featured disputatonal talk, as they disagreed, were not satisfied with the work process and rejected, modified or entirely revised their epistemic object in progress. It also exemplified exploratory talk, as the students explored, negotiated, jointly reasoned, and gave motivations and explanations for the other's arguments and ideas. By doing so, they reached decisions and agreements, and produced epistemic objects and artifacts, successfully solving the learning challenges. In this, the students also made an effort to make their knowledge publicly accountable, first to their comaker(s) and then to their peers and the teacher(s). In students' enactment of the knowledge practices, we have sought to underline the crucial importance of learning from peers. As shown in our examples, the students continuously introduced and demonstrated new ways of working to their peers, and their guidance was more important than the pre-given instructions or the support provided by the teachers in this context.

Along with the language, characteristic in the students' interaction in the FUSE Studio makerspace we studied, were both material and spatial mediation as well as the pivotal role of non-verbal communication when enacting the knowledge practices during STEAM learning. Our study generates new knowledge about the ways the materials of makerspaces become joint attention in ongoing interaction with opportunities and tensions for engagement and learning. The materials and spaces played an important role for the students to communicate, and to establish joint attention, in other words, to coordinate their actions and attention with others on an object (see also Tomasello 2000). Further, the student groups familiarized themselves with negotiated and collectively appropriated tools (also Baker et al. 1999), and the tools then changed and molded their interactions (see also Riikonen et al. 2020). Echoing previous studies on technologically and materially rich learning environments, the students' creation of epistemic objects and artifacts was critically dependent on embodied practices connected to making (Kangas et al. 2013; Blikstein 2013; Kafai et al. 2014). In our study, the students repositioned (by bodily acts) themselves and the materials within the given makerspace room, for example, by relocating from the makerspace to an outside corridor. Also, gestures, such as 
smiles and signs of excitement played a significant role in the enactment of the students' knowledge practices when working with the available conceptual, material and spatial resources.

Our findings point to the need for further investigation of the spatial mediators, namely the physical room and its spatial arrangements in the students' maker work. Adding to the existing research knowledge on makerspaces, our findings highlight the physical space and its organization as an important mediator for the students' knowledge practices as well as their enactment and management of them. The students in our examples chose to carry out maker work in different spaces. Thus, instead of a singular entity, the physical makerspace context and its materials need to be seen as a constellation, providing a variety of opportunities and, in some cases, also constraints for the students' maker work. In light of our findings, the FUSE Studio could be seen as offering a new multi-level instrumentality of learning (see also Engeström 2007), in other words, multi-layered and complex constellations of conceptual, material, embodied and spatial mediators, mediating students' knowledge practices and guiding their activity.

Further, our findings are in line with previous research showing that the presence of heterogeneous learners (also Riikonen et al. 2020; Stahl and Hakkarainen 2020), and the multiple digital and non-digital mediators, often new to the students in a makerspace, can be challenging for the students and may create tensions (also Bråten and Braasch 2017; Ludvigsen 2009). In the FUSE Studio, the students' maker work was not without tensions, as they struggled with the technology and handling the various materials. The pedagogical principles of the FUSE Studio, emphasizing students' own interest and choice, supported their multimodal knowledge practices, but at the same time demanded active participation and a high level of responsibility taking (also Zhang et al. 2009) from the students. Yet, from our perspective, the complexity and tensions involved were not always harmful but also triggered and drove students' collaborative knowledge creation and learning (also Kumpulainen et al. 2019a, b.

To support student-participation, peer tutoring, and learning, the FUSE Studio as a technologyrich makerspace context can be viewed as "a third space" (also Gutiérrez 2008) in which to establish dialogic interaction between the students (Mercer 2005), who hold different knowledge resources (Brown and Campione 1996) and skills and aim for collectively solving challenges. It then provides the students with a learning environment that may support connecting "in deep ways to the life experiences of all students" (see Nasir et al. 2006), to productively apply, use and reflect on their own knowledge. Supporting the multimodal knowledge practices identified in our study with novel pedagogical solutions is important to enhance the students' collaboration and the development of their (and also their teachers) digital competencies. This kind of a learning environment can also offer an important place for enhancing students' management of the design and making activities, knowledge creation and learning.

We understand that our study is small scale and descriptive and hence further research is needed to explore students' multimodal knowledge practices in makerspaces. We suggest that the typology for the analysis of three "archetypical forms" of students' talk (Mercer et al. 1999; Mercer 2005, also Mercer 2019) is a worthwhile starting point for future research to investigate students' collaborative knowledge creation in makerspace contexts. As we demonstrated, it can be extended by applying the knowledge practices approach (Hakkarainen et al. 2004; Hakkarainen 2009; Seitamaa-Hakkarainen et al. 2010), and multimodal interaction analysis (Goodwin 2003; Kress 2010; Streeck et al. 2011; Taylor 2014), to take adequate account of the reciprocal interaction between knowledge creation and students' collaborative practice on the one and, as well as the materiality, spatiality and embodied actions on the other in mediating students' knowledge practices. 
The design and implementation of technology- and materially-rich makerspace learning environments, situated in schools, and new pedagogies suited to them, is not a one-time effort, but a continuous process that includes tensions, modification, implementation and adjusting new and old artifacts, tools, technologies and procedures (see also Engeström 2007). In reporting our findings, we have presented situational examples of the students' interaction and knowledge practices during their design and making activities. In the case of the elementary school that was the focus of our study, the FUSE Studio was embedded in the school's locally-adopted official curriculum (the students frequently attending sessions). We argue that it can thus be regarded as a long-term project, offering a tool to teachers for enhancing educational changes in this particular school, and also in other schools.

In our view, widening the understanding of students' multimodal knowledge practices in makerspaces can provide valuable lessons and guide knowledge advancement and transformation of learning environments in schools. We hope that with our findings, viewing knowledge creation as achieved through a multimodal process, we will be able to further inform the design and implementation of novel pedagogical solutions, to consider and facilitate the management of multiple mediators and peer learning at the intersection between tacit and explicit knowledge in technology- and materially-rich learning environments. At their best, such learning environments can serve as "amalgams of arrangements and mechanisms" (Knorr-Cetina 1999) for collaborative knowledge practices, mediated multimodally. Multimodality is particularly important, often by the support of mediational means other than language, in making visible how the students know and what they know, or do not know, to enhance their creation of meaningful, shared epistemic objects and artifacts, and learning of something that is not yet present and known.

Acknowledgements We thank the three anonymous reviewers and the editor for their insightful comments and suggestions. We are indebted to Pirita Seitamaa-Hakkarainen, Kai Hakkarainen and Sini Riikonen for their excellent guidance and support. We would like to express our gratitude to Jenny Renlund for her assistance in the data analysis. We also want to thank our colleagues in the Learning, Culture and Interventions (LECI) research community, at the University of Helsinki, for helpful comments. This study has been financially supported by a grant from by the Academy of Finland (project no: 310790, PI Kristiina Kumpulainen) entitled Learning by Making: The educational potential of school-based makerspaces for young learners' digital competencies (iMake).

Authors' contributions The two authors contributed equally to the production of this paper.

Availability of data and material Written permission to conduct the research was acquired from the school. The students' guardians were informed about the research and its data collection methods and were asked to give their written consent for their children's participation in the research. The research data cannot be shared outside the research group with any third parties.

\section{Compliance with ethical standards}

Conflicts of interest/competing interests We have no conflicts of interest to declare.

Open Access This article is licensed under a Creative Commons Attribution 4.0 International License, which permits use, sharing, adaptation, distribution and reproduction in any medium or format, as long as you give appropriate credit to the original author(s) and the source, provide a link to the Creative Commons licence, and indicate if changes were made. The images or other third party material in this article are included in the article's Creative Commons licence, unless indicated otherwise in a credit line to the material. If material is not included in the article's Creative Commons licence and your intended use is not permitted by statutory regulation or exceeds the permitted use, you will need to obtain permission directly from the copyright holder. To view a copy of this licence, visit http://creativecommons.org/licenses/by/4.0/. 


\section{References}

Arvaja, M., Salovaara, H., Häkkinen, P., \& Järvelä, S. (2007). Combining individual and group-level perspectives for studying collaborative knowledge construction in context. Learning and Instruction, 17(4), 448459.

Baker, M., Hansen, T., Joiner, R. \& Traum, D. (1999). The role of grounding in collaborative learning tasks, In P. Dillenbourg (Ed.), Collaborative learning: cognitive and computational approaches (pp. 31-63). Pergamon: Elsevier Science.

Bereiter, C., \& Scardamalia, M. (2014). Knowledge building and knowledge creation: One concept, two hills to climb. In S. C. Tan, H. J. So, \& J. Yeo (Eds.), Knowledge creation in education (pp. 35-52). Singapore: Springer.

Bevan, B., Ryoo, J. J., Shea, M., Kekelis, L., Pooler, P., Green, E., Bulalacao, N., McLeod, E., Sandoval, J., \& Hernandez, M. (2016). Making as a strategy for afterschool STEM learning: Report from the Californian tinkering afterschool network research-practice partnership. San Francisco, CA: The Exploratorium.

Blikstein, P. (2013). Digital fabrication and 'making' in education: The democratization of invention. In J. Walter-Herrmann \& C. Büching (Eds.), FabLabs: Of machines, makers and inventors. Bielefeld: Transcript Publishers.

Bråten, I., \& Braasch, J. L. G. (2017). Key issues in research on students' critical Reading and learning in the 21st century information society. In C. Ng C \& B. Bartlett (Eds.), Improving Reading and Reading Engagement in the 21st Century (pp. 77-98). Singapore: Springer.

Brown, A. L., \& Campione, J. C. (1996). Psychological theory and the design of innovative learning environments: On procedures, principles, and systems. In L. Schauble \& R. Glaser (Eds.), Innovations in learning: New environments for education (pp. 289-325). Inc: Lawrence Erlbaum Associates.

Brown, J. S., \& Duguid, P. (2017). The social life of information: Updated, with a new preface. Boston, MA: Harvard Business Review Press.

Cress, U., \& Kimmerle, J. (2008). A systemic and cognitive view on collaborative knowledge building with wikis. International Journal of Computer-Supported Collaborative Learning, 3(2), 105-122.

Damşa, C. I., \& Muukkonen, H. (2020). Conceptualising pedagogical designs for learning through objectoriented collaboration in higher education. Research Papers in Education, 35(1), 82-104.

Damşa, C. I., Kirschner, P. a., Andriessen, J. E. B., Erkens, G., \& Sins, P. H. M. (2010). Shared epistemic agency: An empirical study of an emergent construct. Journal of the Learning Sciences, 19(2), 143-186.

Derry, S. J., Pea, R. D., Barron, B., Engle, R. A., Erickson, F., Goldman, R., ... Sherin, B. L. (2010). Conducting video research in the learning sciences: Guidance on selection, analysis, technology, and ethics. Journal of the Learning Sciences, 19(1), 3-53.

Engeström, Y. (2007). Enriching the theory of expansive learning: Lessons from journeys toward coconfiguration. Mind, Culture, and Activity, 14, 23-39.

Fernández, M., Wegerif, R., Mercer, N., \& Rojas-Drummond, S. (2009). Re-conceptualizing “scaffolding” and the zone of proximal development in the context of symmetrical collaborative learning. The Journal of Classroom Interaction, 50(1), 54-72.

Goodwin, C. (2003). The semiotic body in its environment. In J. Coupland \& R. Gwyn (Eds.), Discourses of the body (pp. 19-42). New York: Palgrave Macmillan.

Greiffenhagen, C. (2012). Making rounds: The routine work of the teacher during collaborative learning with computers. International Journal of Computer-Supported Collaborative Learning, 7, 11-42. https://doi.org/ 10.1007/s11412-011-9134-8.

Gutiérrez, K. D. (2008). Developing a sociocritical literacy in the third space. Reading Research Quarterly, 43, $148-164$.

Gutiérrez, K., Baquedano-López, P., \& Tejeda, C. (1999). Rethinking diversity: Hybridity and hybrid language practices in the third space. Mind, Culture, and Activity, 6, 286-303.

Hakkarainen, K. (2009). A knowledge-practice perspective on technology-mediated learning. International Journal of Computer-Supported Collaborative Learning, 4, 213-231.

Hakkarainen, K., Paavola, S., \& Lipponen, L. (2004). From communities of practice to innovative knowledge communities. LLine - Lifelong Learning in Europe, 9(2), 74-83.

Halverson, E. R., \& Sheridan, K. (2014). The maker movement in education. Harvard Educational Review, 84(4), 495-504.

Härkki, T., Seitamaa-Hakkarainen, P., \& Hakkarainen, K. (2017). Hands on design: Comparing the use of sketching and gesturing in collaborative designing. Journal of Design Research, 16(1), $24-46$.

Hennessy, S., \& Murphy, P. (1999). The Potential for Collaborative Problem Solving in Design and Technology. International Journal of Technology and Design Education, 9, 1-36. 
Hilppö, J., \& Stevens, R. (2020). "Failure is just another try": Re-framing failure in school through the FUSE studio approach. International Journal of Educational Research, 99. https://doi.org/10.1016/j.ijer.2019.10. 004 .

Hmelo-Silver, C. (2003). Analyzing collaborative knowledge construction: Multiple methods for integrated understanding. Computes and Education, 41, 397-420.

Holbert, N. R., \& Wilensky, U. (2014). Constructible authentic representations: Designing video games that enable players to utilize knowledge developed in-game to reason about science. Technology, Knowledge and Learning, 19, 53-79.

Honey, M., \& Kanter, D. (Eds.). (2013). Design, make, play: Growing the next generation of STEM innovators. New York: Routledge.

Illum, B., \& Johansson, M. (2012). Transforming physical materials into artefacts - learning in the school's practice of sloyd. Techne Series A, 19(1), 2-16.

Ingold, T. (2010). The textility of making. Cambridge Journal of Economics, 34, 91-102.

Johnson, B., \& Halverson, E. (2015). Learning in the making: Leveraging technologies for impact. Innovations in Interaction Design \& Learning workshop, IDC, 21, 2015.

Kafai, Y., Fields, D., \& Searle, K. (2014). Electronic textiles as disruptive designs: Supporting and challenging maker activities in schools. Harvard Educational Review, 84(4), 532-556.

Kajamaa, A., \& Kumpulainen, K. (2019). Agency in the Making: Analyzing students' transformative agency in a school-based makerspace. Mind, Culture, and Activity, 26(3), 266-281.

Kajamaa, A., Kumpulainen, K., \& Rajala, A. (2018). Digital learning environment mediating students' funds of knowledge and knowledge creation. Studia Paedagogica, 23(4), 49-66.

Kajamaa, A., Kumpulainen, K., \& Olkinuora, H.-R. (2020). Teacher interventions in students' collaborative work in a technology-rich educational makerspace. British Journal of Educational Technology, 51(2), 371386.

Kangas, K., Seitamaa-Hakkarainen, P., \& Hakkarainen, K. (2013). Design thinking in elementary students' collaborative lamp designing process. Design and Technology: An International Journal, 18(1), $30-43$.

Knorr-Cetina, K. (1999). Epistemic cultures: How the sciences make knowledge. Cambridge, MA: Harvard University Press.

Knorr-Cetina, K. (2001). Objectual practices. In T. Schatzki, K. Knorr-Cetina, \& E. Von Savigny (Eds.), The practice turn in contemporary theory (pp. 175-188). London: Routledge.

Kollar, I., Fischer, F., \& Hesse, F. W. (2006). Collaboration scripts - A conceptual analysis. Educational Psychology Review, 18, 159-185. https://doi.org/10.1007/s10648-006-9007-2.

Koskinen, A., Seitamaa-Hakkarainen, P., \& Hakkarainen, K. (2015). Interaction and embodiment in craft teaching. Techne Series: Research in Sloyd Education and Craft Science A, 22(1), 59-72.

Kress, G. (2010). Multimodality - A social semiotic approach to contemporary communication. London: Routledge.

Kump, B., Moskaliuk, J., Dennerlein, S., \& Ley, T. (2013). Tracing knowledge co-evolution in a realistic course setting: A wiki-based field experiment. Computers \& Education, 69, 60-70.

Kumpulainen, K., \& Kajamaa, A. (2020). Sociomaterial movements of students' engagement in a school's makerspace. British Journal of Educational Technology, 51(4), 1292-1307.

Kumpulainen, K., Kajamaa, A., \& Rajala, A. (2018). Understanding educational change: Agency-structure dynamics in a novel design and making environment. Digital Education Review, 33, 26-38.

Kumpulainen, K., Kajamaa, A., \& Rajala, A. (2019a). Motive-demand dynamics creating a social context for students' learning experiences in a making and design environment. In A. Edwards, M. Fleer, \& L. Bottcher (Eds.), Cultural-historical approaches to studying learning and development: Societal, institutional and personal perspectives (pp. 185-199). Singapore: Springer.

Kumpulainen, K., Rajala, A., \& Kajamaa, A. (2019b). Researching the materiality of communication in an educational makerspace: The meaning of social objects. In N. Mercer, R. Wegerif, \& L. Major (Eds.), The Routledge international handbook of research on dialogic education (pp. 439-453). London: Routledge.

Kumpulainen, K., Kajamaa, A., Leskinen, J., Byman, J., \& Renlund, J. (2020). Mapping digital competence: Students' maker literacies in a school's makerspace. Frontiers in Education, 5(69). https://doi.org/10.3389/ feduc.2020.00069.

Leskinen, J., Kumpulainen, K., Kajamaa, A., \& Rajala, A. (2020). The emergence of leadership in students' group interaction in a school-based makerspace. European Journal of Psychology of Education. https://oi. org/10.1007/s10212-020-00509-x.

Ludvigsen, S. (2009). Sociogenesis and cognition: The struggle between social and cognitive activities. In B. Schwarz, T. Dreyfus, \& R. Hershkowitz (Eds.), Transformation of knowledge through classroom interaction (pp. 281-302). London: Routledge.

Ludvigsen, S. R. (2012). What counts as knowledge: Learning to use categories in computer environments. Learning, Media and Technology, 37(1), 40-52. 
Ludvigsen, S., Lund, A., Rasmussen, I., \& Säljö, R. (Eds.). (2011). Learning across sites: New tools, infrastructures and practices. London: Routledge.

Ludvigsen, S., Cress, U., Law, N., Rosé, C. P., \& Stahl, G. (2016). Collaboration scripts and scaffolding. International Journal of Computer-Supported Collaborative Learning, 11, 381-385. https://doi.org/10. 1007/s11412-016-9247-1.

Mäkitalo, A.. (2011). Professional learning and the materiality of social practice. Journal of Education and Work, 25(1), 59-78.

Marsh, J. (2020). Researching the digital literacy and multimodal practices of young children. A European agenda for change. In O. Erstad, R. Flewitt, B. Kümmerling-Meibauer, \& S. P. Pereira (Eds.), The Routledge handbook of digital literacies in early childhood (pp. 19-30). London: Routledge.

Marsh, J., Kumpulainen, K., Nisha, B., Velicu, A., Blum-Ross, A., Hyatt, D., Jónsdóttir, S. R., et al. (2017). Makerspaces in the early years: A literature review. Makey Project: University of Sheffield.

Martin, A. M., \& Hand, B. (2009). Factors affecting the implementation of argument in the elementary science classroom. A longitudinal case study. Research in Science Education, 39, 17-38. https://doi.org/10.1007/ s11165-007-9072-7.

Mehto, V., Riikonen, S., Hakkarainen, K., Kangas, K., \& Seitamaa-Hakkarainen, P. (2020). Epistemic roles of materiality within a collaborative invention project at a secondary school. British Journal of Educational Technology, 51(4), 1246-1261.

Mercer, N. (1994). The quality of talk in children's joint activity at the computer. Journal of Computer Assisted Learning, 10, 24-32.

Mercer, N. (1995). The guided construction of knowledge: Talk amongst teachers and learners. Multilingual Matters: Clevedon.

Mercer, N. (1996). The quality of talk in children's collaborative activity in the classroom. Learning and Instruction, 6, 359-379.

Mercer, N. (2005). Sociocultural discourse analysis: Analyzing classroom talk as a social mode of thinking. Journal of Applied Linguistics, 1(2), 137-168.

Mercer, N. (2008). The seeds of time: Why classroom dialogue needs a temporal analysis. Journal of the Learning Sciences, 17(1), 33-59.

Mercer, N. (2019). Language and the joint creation of knowledge: The selected works of Neil Mercer. New York: Routledge.

Mercer, N., \& Littleton, K. (2007). Dialogue and the development of children's thinking: A sociocultural approach. New York: Routledge.

Mercer, N., Wegerif, R., \& Daves, L. (1999). Children's talk and the development of reasoning in the classroom. British Educational Research Journal, 25(1), 95-111.

Mercer, N., Hennessy, S., \& Warwick, P. (2019). Dialogue, thinking together and digital technology in the classroom: Some educational implications of a continuing line of inquiry. International Journal of Educational Research, 97, 187-199.

Miettinen, R. (2006). Epistemology of material transformative activity: John Dewey's pragmatism and culturalhistorical activity theory. Journal for the Theory of Social Behaviour, 36(4), 389-408.

Miettinen, R., \& Paavola, S. (2016). Reconceptualizing object construction: The dynamics of building information Modelling in construction design. Information Systems Journal, 28(3), 516-531.

Mondada, L. (2018). The multimodal interactional organization of tasting: Practices of tasting cheese in gourmet shops. Discourse Studies, 20(6), 743-769.

Nasir, N. S., Rosebery, A. S., Warren, B., \& Lee, C. D. (2006). Learning as a cultural process: Achieving equity through diversity. In R. K. Sawyer (Ed.), The Cambridge handbook of: The learning sciences (p. 489-504). Cambridge University Press.

National Academy of Sciences. (2012). A framework for K-12 science education: Practices, crosscutting concepts, and core ideas. Stardards of National Research Council. Washington, DC: The National Academies Press Available at www.nap.edu.

Paavola, S., Lakkala, M., Muukkonen, H., Kosonen, K., \& Karlgren, K. (2011). The roles and uses of design principles for developing the Trialogical approach on learning. Research in Learning Technology, 19(3), 233-246.

Peppler, K., Halverson, E., \& Kafai, Y. B. (Eds.). (2016). Makeology: Makerspaces as learning environments (Vol. 1). New York: Routledge.

Rasmussen, I., \& Damşa, C. I. (2017). Heterochrony through moment-to-moment interaction: A micro-analytical exploration of learning as sense making with multiple resources. International Journal of Educational Research, 84, 79-89.

Riikonen, S., Seitamaa-Hakkarainen, P., \& Hakkarainen, K. (2020). Bringing maker practices to school: Tracing discursive and materially mediated aspects of student teams' collaborative making processes. International Journal of Computer-Supported Collaborative Learning, 15(3), 319-349. 
Ritella, G., \& Hakkarainen, K. (2012). Instrument genesis in technology mediated learning: From double stimulation to expansive knowledge practices. International Journal of Computer-Supported Collaborative Learning, 7, 239-258.

Rojas-Drummond, S., Hernández, G., Vélez, M., \& Villagrán, G. (1998). Cooperative learning and the appropriation of procedural knowledge by primary school children. Learning and Instruction, 8(1), 37-61.

Rowell, P. M. (2002). Peer interactions in shared technological activity: A study of participation. International Journal of Technology and Design Education, 12(1), 1-22.

Säljö, R. (1999). Learning as the use of tools: A socio-cultural perspective on the human-technology link. In K. Littleton \& P. Light (Eds.), Learning with computers: Analysing productive interaction (pp. 144-163). London: Routledge.

Sampson, V., Grooms, J., \& Walker, J. P. (2011). Argument-driven inquiry as a way to help students learn how to participate in scientific argumentation and craft written arguments: An exploratory study. Science Education, 95(2), 217-257.

Sandoval, W., \& Reiser, B. (2004). Explanation-driven inquiry: Integrating conceptual and epistemic scaffolds for scientific inquiry. Science Education, 88(3), 345-372.

Sawyer, K. (2012). Extending sociocultural theory to group creativity. Vocations and Learning, 5, 59-75.

Scardamalia, M. (2002). Collective cognitive responsibility for the advancement of knowledge. In B. Smith \& C. Bereiter (Eds.), Liberal education in a knowledge society (pp. 67-98). Berkeley, CA: Distributed by Publishers Group West.

Scardamalia, M., \& Bereiter, C. (1994). Computer support for knowledge-building communities. Journal of the Learning Sciences, 3(3), 265-283.

Scardamalia, M., \& Bereiter, C. (2014). Knowledge building and knowledge creation: Theory, pedagogy, and technology. In K. Sawyer (Ed.), Cambridge handbook of the learning sciences (pp. 397-417). New York: Cambridge University Press.

Scardamalia, M., Bransford, J., Kozma, B., \& Quellmalz, E. (2012). New assessments and environments for knowledge building. In P. Griffin, B. McGraw, \& E. Care (Eds.), Assessment and teaching of 21st century skills (pp. 231-300). New York, NY: Springer Science+Business Media.

Schatzki, T. R. (1996). Social practices: A Wittgensteinian approach to human activity and the social. Cambridge: Cambridge University Press.

Schatzki, T. R. (2001). Introduction: Practice theories. In T. R. Schatzki, K. Knorr-Cetina, \& E. von Savigny (Eds.), The practice turn in contemporary theory (pp. 1-14). London and New York: Routledge.

Schmidt, R., \& Volbers, J. (2011). Siting praxeology. The methodological significance of "public" in theories of social practice. Journal for the Theory of Social Behaviour, 41(4), 419-440.

Schrock, A, R. (2014). Education in disguise: Culture of a hacker and maker space. InterActions: UCLA Journal of Education and Information Studies, 10(1). Retrieved from https://escholarship.org/uc/item/0js1n1qg.

Seitamaa-Hakkarainen, P., Viilo, M., \& Hakkarainen, K. (2010). Learning by collaborative designing: Technology-enhanced knowledge practices. International Journal of Technology and Design Education, 2(2), 109-136.

Smith, W., \& Smith, B. C. (2016). Bringing the maker movement to school. Fourth grade students create projects to illustrate the transfer and transformation of energy. Science and Children, 54(1), 30-37.

Stahl, G., \& Hakkarainen, K. (2020). Theories of CSCL. To appear. In U. Cress, C. Rose, S. Wise, \& J. Oshima (Eds.), International handbook of computer supported collaborative learning. London: Springer.

Stevens, R., \& Jona, K. (2017). Program design. FUSE studio -website. Retrieved May 20, 2017 from https:// www.fusestudio.net/program-design

Stevens, R., Jona, K., Penney, L., Champion, D., Ramey, K., Hilppö, J., ... Penuel, W. (2016). FUSE: An alternative infrastructure for empowering learners in schools. In C-K. Looi, J. Polman, U. Cress, \& P. Reimann (Eds.) Transforming Learning, Empowering Learners: 12th International Conference of the Learning Sciences (pp. 1025-1032). Retrieved from: https:/www.isls.org/icls/2016/docs/ICLS2016_ Volume_2.pdf

Streeck, J., Goodwin, C., \& LeBaron, C. (2011). Embodied interaction: Language and body in the material world. Cambridge: Cambridge University Press.

Strømme, T. A., \& Furberg, A. (2015). Exploring teacher intervention in the intersection of digital resources, peer collaboration, and instructional design. Science Education, 99(5), 837-862.

Suthers, D. D. (2006). Technology affordances for intersubjective meaning making: A research agenda for CSCL. Computer Supported Learning, 1, 315-337.

Taylor, R. (2014). Meaning between, in, and around words, gestures and postures: Multimodal meaning making in children's classroom communication. Language and Education, 28(5), 401-420.

Tomasello, M. (2000). Culture and cognitive development. Current Directions in Psychological Science, 9(2), $37-40$. 
Van Maanen, J., Sørensen, J. B., \& Terence, R. M. (2007). The interplay between theory and method. Academy of Management Review, 32(4), 1145-1154.

Vygotsky, L. S. (1978). Mind in society: The development of higher mental processes. Cambridge, MA: Harvard University Press.

Vygotsky, L. (1986). Thought and language. Cambridge MA: Massachusetts Institute of Technology.

Wegerif, R. (1996). Using computers to help coach exploratory talk across the curriculum. Computers and Education, 26(1-3), 51-60.

Wertsch, J. V. (1991). Voices of the mind. New York: Harvester.

Yeh, Y., Yeh, Y., \& Chen, Y.-H. (2012). From knowledge sharing to knowledge creation: A blended knowledgemanagement model for improving university students' creativity. Thinking Skills and Creativity, 7(3), 245257.

Zhang, J. W., Scardamalia, M., Reeve, R., \& Messina, R. (2009). Designs for collective cognitive responsibility in knowledge-building communities. Journal of the Learning Sciences, 18(1), 7-44.

Zhang, J. W., Tao, D., Chen, M.-H., Sun, Y., Judson, D., \& Naqvi, S. (2018). Co-organizing the collective journey of inquiry with idea thread mapper. Journal of the Learning Sciences, 27(3), 390-430.

Publisher's note Springer Nature remains neutral with regard to jurisdictional claims in published maps and institutional affiliations. 